\title{
Infrared and millimetre-wave scintillometry in the suburban environment - Part 1: Structure parameters
}

\author{
H. C. Ward ${ }^{1,2,3}$, J. G. Evans ${ }^{1}$, C. S. B. Grimmond ${ }^{2,3}$, and J. Bradford ${ }^{4}$ \\ ${ }^{1}$ Centre for Ecology and Hydrology, Wallingford, Oxfordshire, OX10 8BB, UK \\ ${ }^{2}$ Department of Geography, King's College London, London, WC2R 2LS, UK \\ ${ }^{3}$ Department of Meteorology, University of Reading, Reading, RG6 6BB, UK \\ ${ }^{4}$ Space Science Department, Rutherford Appleton Laboratory, Didcot, Oxfordshire, OX11 0QX, UK \\ Correspondence to: H. C. Ward (h.c.ward@ reading.ac.uk)
}

Received: 3 October 2014 - Published in Atmos. Meas. Tech. Discuss.: 17 November 2014

Revised: 10 February 2015 - Accepted: 28 February 2015 - Published: 20 March 2015

\begin{abstract}
Scintillometry, a form of ground-based remote sensing, provides the capability to estimate surface heat fluxes over scales of a few hundred metres to kilometres. Measurements are spatial averages, making this technique particularly valuable over areas with moderate heterogeneity such as mixed agricultural or urban environments. In this study, we present the structure parameters of temperature and humidity, which can be related to the sensible and latent heat fluxes through similarity theory, for a suburban area in the UK. The fluxes are provided in the second paper of this two-part series. A millimetre-wave scintillometer was combined with an infrared scintillometer along a $5.5 \mathrm{~km}$ path over northern Swindon. The pairing of these two wavelengths offers sensitivity to both temperature and humidity fluctuations, and the correlation between wavelengths is also used to retrieve the path-averaged temperature-humidity correlation. Comparison is made with structure parameters calculated from an eddy covariance station located close to the centre of the scintillometer path. The performance of the measurement techniques under different conditions is discussed. Similar behaviour is seen between the two data sets at sub-daily timescales. For the two summer-to-winter periods presented here, similar evolution is displayed across the seasons. A higher vegetation fraction within the scintillometer source area is consistent with the lower Bowen ratio observed (midday Bowen ratio $<1$ ) compared with more built-up areas around the eddy covariance station. The energy partitioning is further explored in the companion paper.
\end{abstract}

\section{Introduction}

Scintillometry provides turbulent heat fluxes representative of much larger scales than is possible with traditional pointbased or small-area measurements, such as eddy covariance (EC). The technique relates fluctuations in the intensity of light ("scintillations", observed as shimmering or "heathaze") to the strength of turbulence in the atmosphere. Scintillometry is suited to heterogeneous regions because the measurements are spatially integrated, providing average values representative of the area as a whole (Hoedjes et al., 2002; Meijninger et al., 2002b; Evans et al., 2012). A transmitter unit provides the light source, a beam of electromagnetic radiation, which is detected some distance $(0.1-10 \mathrm{~km})$ away by the receiver. Variations in the received intensity result from diffraction; as turbulent eddies move through the beam, their refractive indices are determined by their densities which, in turn, can be related to their temperature and moisture content (e.g. Meijninger, 2003). The refractive index depends on the wavelength of radiation; in the optical or near-infrared range temperature-induced fluctuations dominate the refractive index fluctuations, whereas for longer wavelengths (millimetre or radiowave regions) humidity fluctuations are more important. Scintillometers are most sensitive to fluctuations occurring towards the centre of the path, i.e. away from the transmitter and receiver and their mountings. Thus the atmosphere above a city (or valley) can be sampled remotely - a major advantage in areas where it would be impracticable to install equipment in situ. 
Scintillometer measurements have been carried out at sites of varying complexity, from tests of the technique under simple conditions (Hill and Ochs, 1978; De Bruin et al., 1993) to studies investigating the complications of non-ideal terrain, including heterogeneous land cover (Beyrich et al., 2002; Meijninger et al., 2002a, 2006; Ezzahar et al., 2007) and complex topography (Poggio et al., 2000; Evans, 2009; Evans et al., 2012). On the whole, these studies have shown that scintillometers installed above or close to the blending height can provide valuable area-averaged fluxes.

With careful selection of a suitable path, the scintillometry technique has been successfully used in urban areas. Kanda et al. (2002), the first to obtain the sensible heat flux in an urban setting, used two small aperture scintillometers installed at different heights on a $250 \mathrm{~m}$ path over a dense residential area of Tokyo. Other small aperture studies include measurements in Basel (Roth et al., 2006) and London (Pauscher, 2010). Large aperture scintillometers are increasingly being used over longer urban paths (Lagouarde et al., 2006; Gouvea and Grimmond, 2010; Mestayer et al., 2011; Wood et al., 2013; Zieliński et al., 2013). These infrared (or optical) scintillometers must rely on the residual of the energy balance if the latent heat flux is to be estimated. However, the complexity of the energy balance (Oke, 1987) means this is usually not attempted in urban areas. In particular the significant storage heat flux (Offerle et al., 2005) and contribution from anthropogenic activities (Klysik, 1996; Allen et al., 2011) are both very difficult to measure.

Sensitivity to both humidity and temperature fluctuations can be achieved with a two-wavelength scintillometer system. In this case, the structure parameter of humidity can be obtained in addition to the structure parameter of temperature, from which both the sensible heat flux $\left(Q_{\mathrm{H}}\right)$ and latent heat flux $\left(Q_{E}\right)$ can be found (Hill et al., 1988; Andreas, 1989). Several studies have reported successful estimates of $Q_{E}$ using the two-wavelength method (Meijninger et al. 2002a, 2006; Evans, 2009; Evans et al., 2010). This technique requires that a value of the temperature-humidity correlation coefficient, $r_{T q}$, be assumed. Often $r_{T q}$ is taken to be \pm 1 , indicating perfect correlation, as in Green et al. (2001) and Meijninger et al. (2002a), but other values have also been used: Kohsiek and Herben (1983) used $r_{T q}=0.87$; Evans (2009) used $r_{T q}=0.8$; and Meijninger et al. (2006) used measured $r_{T q}$ from a nearby EC station with values between -0.5 and 0.9 . Previous studies measuring $r_{T q}$ with fast-response sensors suggest daytime values tend to be smaller than 1 , typically around 0.8 . For example: 0.75 at a flat, homogeneous site (Kohsiek, 1982); 0.76 over sandy soil with patchy vegetation (Andreas et al., 1998); 0.700.95 for unstable conditions over heterogeneous farmland (Meijninger et al., 2002a). Nocturnal values of $r_{T q}$ down to -1 are rarely seen (Andreas et al., 1998; Beyrich et al., 2005; Meijninger et al., 2006).

Some studies have suggested that $r_{T q}$ varies with stability (Li et al., 2011; Nordbo et al., 2013), although others have shown no clear relation (De Bruin et al., 1993; Roth, 1993). Explanation of $\left|r_{T q}\right| \neq 1$ is often related to surface heterogeneity (Roth, 1993; Andreas et al., 1998; Lüdi et al., 2005) but low values have been obtained over homogeneous surfaces too (Kohsiek, 1982; De Bruin et al. 1993). In almost all previous studies, measurements of $r_{T q}$ were made using point sensors.

Lüdi et al. (2005) outlined a method to obtain pathaveraged values of $r_{T q}$ using a two-wavelength scintillometer system. This "bichromatic-correlation" method is an extension of the two-wavelength technique and involves correlating the signals from each scintillometer, thus enabling determination of the combined temperature-humidity fluctuations and $r_{T q}$. The bichromatic-correlation method, applied for the first time during the LITFASS-2003 campaign, gave promising results (Beyrich et al., 2005; Lüdi et al., 2005). An overview of the second study, during LITFASS-2009, is given in Beyrich et al. (2012).

Aside from enabling more accurate structure parameters and fluxes to be obtained from scintillometry, improved knowledge of $r_{T q}$ has wider applications. Correlations between scalars are thought to be useful indicators for the violation of Monin-Obukhov similarity theory (MOST) (Hill, 1989; Andreas et al., 1998). Correlations are also relevant to the understanding and modelling of turbulent transport processes through physical quantities such as eddy diffusivities.

The objectives of this research are to measure structure parameters and obtain large-area sensible and latent heat fluxes for a suburban area. In this two-part study, a $94 \mathrm{GHz}$ millimetre-wave scintillometer was deployed alongside an infrared scintillometer over the town of Swindon, UK. This is the first use of such a system in the urban environment. In Part 1, structure parameters from the two-wavelength system are compared to structure parameters calculated from an EC system and measured values of $r_{T q}$ are discussed. In Part 2 (Ward et al., 2015), the sensible and latent heat fluxes are determined and analysed. These spatially integrated observations represent the behaviour of the suburban surface over an area of $5-10 \mathrm{~km}^{2}$ and constitute by far the longest data set (14 months) that uses these techniques. The performance of the techniques is assessed under a range of conditions, and their strengths and weaknesses are examined. This paper offers insight into the behaviour of the structure parameters and $r_{T q}$ at various timescales (daily, seasonal and inter-annual), including how they respond to energy and water availability, surface cover and changing meteorological conditions.

\section{Theory}

Structure parameters describe the intensity of turbulent fluctuations in the atmosphere. The structure parameter for a variable, $y$, is defined (Tatarski, 1961); 
$C_{y}^{2}=\frac{\overline{[y(x+\delta)-y(x)]^{2}}}{\delta^{2 / 3}}$,

where $\delta$ is the spatial separation between two points and $y(x)$ is the value of the variable at location $x$. The cross-structure parameter between two variables is defined analogously; for example the cross-structure parameter between temperature, $T$, and specific humidity, $q$, is written as follows:

$C_{T q}=\frac{\overline{[T(x+\delta)-T(x)][q(x+\delta)-q(x)]}}{\delta^{2 / 3}}$.

\subsection{Obtaining structure parameters from scintillometry}

The refractive index structure parameter $\left(C_{n}^{2}\right)$ is fundamental to scintillometry. For each wavelength, $\lambda$, it can be written (Hill et al., 1980) as follows:

$C_{n}^{2}=\frac{A_{T}^{2}}{T^{2}} C_{T}^{2}+2 \frac{A_{T} A_{q}}{T q} C_{T q}+\frac{A_{q}^{2}}{q^{2}} C_{q}^{2}$,

where $C_{T}^{2}$ is the structure parameter of temperature, $C_{q}^{2}$ the structure parameter of specific humidity, $C_{T q}$ the temperature-humidity cross-structure parameter and $A_{T}$ and $A_{q}$ are the structure parameter coefficients for temperature and specific humidity, respectively, given in Ward et al. (2013b) as $A_{t}$ and $A_{q}$ (see their Table 2). These coefficients contain the wavelength dependence of $C_{n}^{2}$, whereas $C_{T}^{2}, C_{q}^{2}$ and $C_{T q}$ are properties of the atmosphere. Each $C_{n}^{2}$ measurement is made up of a combination of the three unknowns: $C_{T}^{2}, C_{q}^{2}$ and $C_{T q}$.

As $C_{n}^{2}$ from large aperture optical or near-infrared scintillometers is almost entirely made up of temperature fluctuations $\left(C_{T}^{2}\right)$, the (usually small) contributions from $C_{T q}$ and $C_{q}^{2}$ can be approximated using the Bowen ratio, $\beta$ (Wesely, 1976; Moene, 2003):

$$
\begin{aligned}
C_{n}^{2} & \approx \frac{A_{T}^{2}}{T^{2}} C_{T}^{2}\left(1+\frac{A_{q}}{q} \frac{T}{A_{T}} \frac{c_{\mathrm{p}}}{L_{\mathrm{v}}} \beta^{-1}\right)^{2} \\
& \approx \frac{A_{T}^{2}}{T^{2}} C_{T}^{2}\left(1+0.03 \beta^{-1}\right)^{2}
\end{aligned}
$$

where $c_{\mathrm{p}}$ is the specific heat capacity of air at constant pressure, $L_{\mathrm{V}}$ is the latent heat of vaporisation and the value 0.03 is for typical atmospheric conditions $(T=300 \mathrm{~K}$, pressure $\left.(p)=10^{5} \mathrm{~Pa}\right)$. The required Bowen ratio may be found by using the available energy as an input to the iteration to obtain the sensible heat flux (e.g. Green and Hayashi, 1998; Meijninger et al., 2002b; Solignac et al., 2009). Calculation of the latent heat flux must rely on the energy balance (Ezzahar et al., 2009; Guyot et al., 2009; Evans et al., 2012; Samain et al., 2012b). This is the single-wavelength scintillometry method.

As demonstrated by Hill et al. (1988) and Andreas (1989), a two-wavelength scintillometer system enables retrieval of both $C_{T}^{2}$ and $C_{q}^{2}$ via simultaneous equations (Eq. (3) for each wavelength). The two-wavelength method has the significant advantage of providing both sensible and latent heat fluxes without resorting to the energy balance, but a value for the temperature-humidity correlation coefficient $r_{T q}$ must be assumed in the substitution $C_{T q}=r_{T q}\left(C_{T}^{2} C_{q}^{2}\right)^{1 / 2}$.

The bichromatic-correlation method uses the same combination of optical and millimetre wavelength scintillometers as for the two-wavelength method, but additionally exploits the correlation between optical and millimetre-wave signals to obtain a third equation for the cross-structure parameter, $C_{n 1 n 2}$ (Lüdi et al. 2005):

$$
\begin{aligned}
C_{n 1 n 2} & =\frac{A_{T 1} A_{T 2}}{T^{2}} C_{T}^{2}+\left(\frac{A_{T 1} A_{q 2}+A_{T 2} A_{q 1}}{T q}\right) C_{T q} \\
& +\frac{A_{q 1} A_{q 2}}{q^{2}} C_{q}^{2},
\end{aligned}
$$

where the subscripts 1 and 2 refer to the different wavelengths. In this study, $\lambda_{1}$ denotes optical (specifically $\left.880 \times 10^{-9} \mathrm{~m}\right)$ and $\lambda_{2}$ millimetre $\left(3.2 \times 10^{-3} \mathrm{~m}\right)$ wavelengths. Thus all three unknown meteorological structure parameters $\left(C_{T}^{2}, C_{q}^{2}\right.$ and $\left.C_{T q}\right)$ can be found from the three measured refractive index structure parameters by inverting the matrix equation (Lüdi et al., 2005):

$$
\left(\begin{array}{lll}
C_{n 1 n 1} & C_{n 2 n 2} & C_{n 1 n 2}
\end{array}\right)=\mathbf{M}\left(\begin{array}{c}
C_{T}^{2} \\
C_{T q} \\
C_{q}^{2}
\end{array}\right),
$$

where the inverse matrix $\mathbf{M}^{-1}$ is given by

$$
\begin{aligned}
\mathbf{M}^{-1} & =\frac{T^{2} q^{2}}{\left(A_{T 1} A_{q 2}-A_{T 2} A_{q 1}\right)^{2}} \\
& \times\left(\begin{array}{ccc}
\frac{A_{q 2}^{2}}{q^{2}} & \frac{A_{q 1}^{2}}{q^{2}} & \frac{-2 A_{q 1} A_{q 2}}{q^{2}} \\
\frac{-A_{T 2} A_{q 2}}{T q} & \frac{-A_{T 1} A_{q 1}}{T q} & \frac{\left(A_{T 1} A_{q 2}+A_{T 2} A_{q 1}\right)}{T q} \\
\frac{A_{T 2}^{2}}{T^{2}} & \frac{A_{T 1}^{2}}{T^{2}} & \frac{-2 A_{T 1} A_{T 2}}{T^{2}}
\end{array}\right) .
\end{aligned}
$$

As mentioned above, the structure parameter coefficients $A_{T}$ and $A_{q}$ should be those formulated using specific humidity.

For the bichromatic-correlation method, the value of $C_{T q}$ can therefore be used to effectively measure the temperaturehumidity correlation coefficient:

$r_{T q}=\frac{C_{T q}}{\sqrt{C_{T}^{2} C_{q}^{2}}}$.

If MOST assumptions (i.e. $T-q$ similarity) are satisfied, the Bowen ratio can be calculated from the structure parameters (Andreas, 1990; Lüdi et al., 2005)

$\beta=\operatorname{sgn}\left[C_{T q}\right] \frac{c_{\mathrm{p}}}{L_{\mathrm{v}}} \sqrt{\frac{C_{T}^{2}}{C_{q}^{2}}}$.

When the cross-structure parameter has not been measured, the structure parameters $C_{T}^{2}$ and $C_{q}^{2}$ can be calculated from the two-wavelength equations, after Hill et al. (1988): 
$C_{T}^{2}=\frac{A_{q 2}^{2} C_{n 1 n 1}+A_{q 1}^{2} C_{n 2 n 2}+2 r_{T q} A_{q 1} A_{q 2} S_{2 \lambda} \sqrt{C_{n 1 n 1} C_{n 2 n 2}}}{\left(A_{T 1} A_{q 2}-A_{T 2} A_{q 1}\right)^{2} T^{-2}}$,

$C_{q}^{2}=\frac{A_{T 2}^{2} C_{n 1 n 1}+A_{T 1}^{2} C_{n 2 n 2}+2 r_{T q} A_{T 1} A_{T 2} S_{2 \lambda} \sqrt{C_{n 1 n 1} C_{n 2 n 2}}}{\left(A_{T 1} A_{q 2}-A_{T 2} A_{q 1}\right)^{2} q^{-2}}$,

where $S_{2 \lambda}$ is \pm 1 . This choice of sign is an inherent ambiguity of the two-wavelength method and represents two possible solutions to $C_{n 2 n 2}$ (Hill et al., 1988; Hill, 1997). For low $\beta$, when humidity fluctuations dominate $C_{n 2 n 2}$ then $S_{2 \lambda}=+1$, whereas $S_{2 \lambda}=-1$ is required at larger $\beta$. The sign of $S_{2 \lambda}$ is not known a priori but must be assumed. Often the two solutions for $\beta$ indicate which is the most likely solution for the atmospheric conditions and site characteristics (Hill, 1997). When expressed as a function of $\beta$, a minimum in $C_{n 2 n 2}$ is revealed due to the coefficients $A_{T}$ and $A_{q}$ having opposite signs at millimetre wavelengths. The contribution of $C_{T q}$ to $C_{n 2 n 2}$ (middle term in Eq. 3) is negative when $C_{T q}>0$, so for moderate $\beta$ the terms in Equation 3 can cancel out leaving $C_{n 2 n 2}$ close to zero (Hill et al., 1988; Otto et al., 1996). In practice, zero $C_{n 2 n 2}$ will not be observed because the instrument has a finite noise floor (and $r_{T q} \neq 1$ ). Instead the scintillation signal may be close to, or below, the detection limit of the instrument, resulting in reduced sensitivity around the region of minimum $C_{n 2 n 2}$ and a tendency for the derived $\beta$ to be biased away from (below, for $S_{2 \lambda}=+1$ ) the value at which minimum $C_{n 2 n 2}$ occurs. The problematic region is expected to occur for $\beta \approx 2-3$ (Leijnse et al., 2007; Ward et al., 2013b).

\subsection{Obtaining structure parameters from eddy covariance}

Conversion between spatial and temporal domains enables calculation of structure parameters from point measurements, such as those from EC instrumentation. The spatial structure function, $D_{y y_{-} x}$, can be written (e.g. Stull, 1988) as follows:

$D_{y y_{-} x}(\delta)=\overline{[y(x+\delta)-y(x)]^{2}}$.

Analogously the temporal structure function, $D_{y y_{-} t}$, is given by

$$
D_{y y_{-} t}(\tau)=\overline{[y(t+\tau)-y(t)]^{2}},
$$

where $\tau$ is the temporal separation and $y(t)$ is the value of the variable at time $t$. Bosveld (1999) gives the conversion between temporal and spatial structure functions using the horizontal wind vector, $\boldsymbol{U}$, and the variances of the three wind components, $\sigma_{u, v, w}^{2}$ :

$D_{y y_{-} x}(\delta)=\frac{D_{y y_{-} t}(\delta / \boldsymbol{U})}{\left(1-\frac{1}{9} \frac{\sigma_{u}^{2}}{U^{2}}+\frac{1}{3} \frac{\sigma_{v}^{2}}{U^{2}}+\frac{1}{3} \frac{\sigma_{w}^{2}}{U^{2}}\right)}$.

Thus temporal structure functions (Eq. 12) can be calculated from EC measurements, converted to spatial structure functions (Eq. 13) and then structure parameters
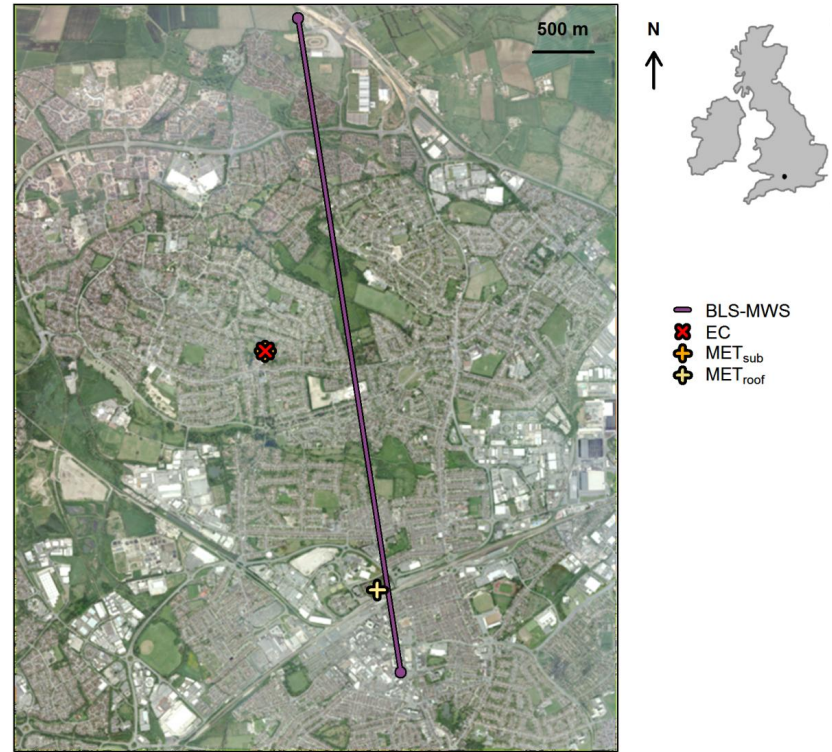

Figure 1. Aerial photograph $\left(2009\right.$, GeoPerspectives $\left.{ }^{\circledR}\right)$ of the study area showing the locations of the two-wavelength scintillometer path (BLS-MWS), eddy covariance station (EC) and two meteorological stations ( $\left.\mathrm{MET}_{\text {sub }}, \mathrm{MET}_{\text {roof }}\right)$. The location of Swindon within the British Isles is shown (top right panel).

$\left(C_{y}^{2}=D_{y y_{-} x}(\delta) \delta^{-2 / 3}\right.$ defines $C_{y}^{2}$ for $\delta$ in the inertial subrange). Unlike fluxes, structure parameters are strongly height dependent.

\section{Experimental details}

\subsection{Instrumental setup and site description}

A millimetre-wave scintillometer (MWS) (Evans, 2009), designed and built by the Centre for Ecology and Hydrology (CEH) and Rutherford Appleton Laboratory (RAL), was used in combination with a commercially available large aperture infrared scintillometer, the BLS900 (Scintec, Rottenburg, Germany). Both scintillometers were installed on a $5.5 \mathrm{~km}$ path over the town of Swindon, UK. The path is orientated approximately north-south $\left(170^{\circ}\right)$ and extends from the edge of the settlement to the town centre (Fig. 1). An EC system, consisting of a sonic anemometer (R3, Gill Instruments, Lymington, UK) and open-path infrared gas analyser (IRGA) (LI-7500, LI-COR Biosciences, Lincoln, USA) mounted at $12.5 \mathrm{~m}$ above ground level (a.g.l.), was positioned near the centre of the path. The EC site was equipped with an automatic weather station (WXT 510/520, Vaisala, Finland) which provides the additional input data required to process the scintillometer data; temperature, relative humidity $(\mathrm{RH})$, pressure and wind speed $(U)$ are measured at a height of $10.6 \mathrm{~m}$. A four-component radiometer (NR01, Hukseflux, The Netherlands) was installed at $10.1 \mathrm{~m}$ on the same mast and a tipping bucket rain gauge $(0.2 \mathrm{~mm}$ tip, Casella CEL, 
Table 1. The instrumental setup. For the scintillometers the mean height of the beam above the land surface $\left(z_{\mathrm{m}}\right)$ is given (for the effective measurement height $\left(z_{\mathrm{ef}}\right)$ see Table 2); for $\mathrm{MET}_{\text {roof }}$ the heights above the roof surface are given. Roughness length, $z_{0}$, and displacement height, $z_{\mathrm{d}}$, were not calculated for the rooftop site. Tx denotes transmitter, Rx receiver.

\begin{tabular}{|c|c|c|c|c|c|}
\hline Instrumentation & Height [m] & Location & $\begin{array}{c}\text { Path } \\
\text { length } \\
{[\mathrm{m}]}\end{array}$ & $\begin{array}{c}z_{0} \\
{[\mathrm{~m}]}\end{array}$ & $\begin{array}{c}z_{\mathrm{d}} \\
{[\mathrm{m}]}\end{array}$ \\
\hline $\begin{array}{l}\text { Two-wavelength } \\
\text { scintillometer system }\end{array}$ & 44.3 & $\begin{array}{l}51^{\circ} 36^{\prime} 33.9^{\prime \prime} \mathrm{N} 1^{\circ} 47^{\prime} 38.6^{\prime \prime} \mathrm{W}(\mathrm{Tx}) \\
51^{\circ} 33^{\prime} 38.1^{\prime \prime} \mathrm{N} 1^{\circ} 46^{\prime} 55.3^{\prime \prime} \mathrm{W}(\mathrm{Rx})\end{array}$ & 5492 & 0.7 & 4.9 \\
\hline EC station & 12.5 & $51^{\circ} 35^{\prime} 4.6^{\prime \prime} \mathrm{N} 1^{\circ} 47^{\prime} 53.2^{\prime \prime} \mathrm{W}$ & - & 0.5 & 3.5 \\
\hline $\mathrm{MET}_{\text {sub }}$ & $\begin{array}{l}10.6(\mathrm{WXT}) \\
10.1(\mathrm{NR} 01)\end{array}$ & $51^{\circ} 35^{\prime} 4.6^{\prime \prime} \mathrm{N} 1^{\circ} 47^{\prime} 53.2^{\prime \prime} \mathrm{W}$ & - & 0.5 & 3.5 \\
\hline $\mathrm{MET}_{\text {roof }}$ & $\begin{array}{l}2.0(\mathrm{WXT}) \\
1.1(\mathrm{NR} 01)\end{array}$ & $51^{\circ} 34^{\prime} 0.3^{\prime \prime} \mathrm{N} 1^{\circ} 47^{\prime} 5.3^{\prime \prime} \mathrm{W}$ & - & - & - \\
\hline
\end{tabular}

Bedford, UK) near the base of the mast. These were located in the garden of a residential property approximately $3 \mathrm{~km}$ north of the town centre, where the surrounding land use is predominantly residential, consisting of 1-2 storey houses with gardens. Full details are given in Ward et al. (2013a). In addition to the meteorological instrumentation at the EC site $\left(\mathrm{MET}_{\mathrm{sub}}\right)$, a second weather station was established on the rooftop of a modern office building close to the town centre $\left(\mathrm{MET}_{\text {roof }}\right)$. The setup is summarised in Table 1. To provide a combined data set of continuous input variables required for scintillometry processing, $T, \mathrm{RH}, p$ and $U$ from $\mathrm{MET}_{\text {roof }}$ were linearly adjusted to gap-fill $\mathrm{MET}_{\text {sub }}$ (required for $<1 \%$ of $T$, RH and $p$ and $<2 \%$ of $U$ data), based on regressions with concurrent data from MET $_{\text {sub }}$ (9 May 2011-31 December 2012).

Northern Swindon is typical of suburban areas in the UK. The area has a relatively large proportion of vegetation and there is a large nature reserve just north of the centre of the study area, which lies directly underneath the scintillometer path. The town centre at the south of the study area has the highest density of buildings and roads (Fig. 1). Industrial areas to the east and southwest with little vegetation contribute to measurement source areas under stable conditions (see Part 2). Despite the variety of land-cover types, many neighbourhoods appear fairly homogeneous at a scale of a few hundred metres. The area shown in Fig. 1 has land cover that is $14 \%$ buildings, $31 \%$ impervious, $53 \%$ vegetation, $1 \%$ water and $2 \%$ pervious. Land cover, topography and building and tree heights were derived from a spatial database for Swindon (5 m resolution, see Ward et al. (2013a) for more information).

To obtain representative measurements it is important to be high enough above the surface that quantities are sufficiently well-blended (i.e. high enough that turbulent mixing averages out the influence of surface heterogeneity), although recent studies have shown successful use of scintillometers even below the blending height (Meijninger et al., 2002b; Ez- zahar et al., 2007). Based on the average height of the roughness elements (i.e. buildings and trees) the blending height is estimated at about $15-30 \mathrm{~m}$ for the BLS-MWS source area (Pasquill, 1974; Garratt, 1978). The scintillometer transmitters, mounted on custom-built brackets, were installed at $28 \mathrm{~m}$ a.g.l. on a television transmitter mast. The receivers of the BLS-MWS system were mounted at $26 \mathrm{~m}$ a.g.l. on a rooftop in Swindon town centre. The resulting path is slanted (Fig. 2).

The effective heights of the scintillometers are given in Table 2, calculated according to the stability independent approximation (Eq. (15) of Hartogensis et al., 2003). These estimates include adjustment to account for the curvature of the earth and displacement height, $z_{\mathrm{d}}$ (Table 1). Displacement heights were calculated from the mean height of the roughness elements, $z_{\mathrm{H}}$, within a distance of $\pm 1000 \mathrm{~m}$ perpendicular to the scintillometer path (and $+500 \mathrm{~m}$ in the direction parallel to the path), using the rule-of-thumb $z_{\mathrm{d}}=0.7 z_{\mathrm{H}}$ (Garratt, 1992; Grimmond and Oke, 1999). In the case of the EC station, $z_{\mathrm{H}}$ was calculated within $500 \mathrm{~m}$ of the EC mast. The difference in BLS and MWS path-weighting functions (Fig. 3) means that the BLS, MWS and combined BLSMWS covariance measurements are representative of different heights even though the BLS and MWS beams essentially traverse the same path (Evans and De Bruin, 2011).

For the two-wavelength scintillometer system the BLS and MWS beams must be close together (Lüdi et al., 2005). The separation between beams was minimised $(<0.35 \mathrm{~m})$, and the relative positions of the BLS and MWS were reversed at each end of the path so that the beams crossed near the centre of the path. It was necessary to shield cables at the scintillometer sites to protect against electrical interference. Scintillometer data can sometimes be affected by vibrations of the mounting structures (Von Randow et al., 2008; Beyrich et al., 2012). However, mounting brackets were designed with this in mind and the scintillometer spectra show little evidence of any vibrational contamination. 
Table 2. Instrument and site-dependent characteristics of the scintillometers and paired scintillometer system.

\begin{tabular}{|c|c|c|c|c|c|}
\hline \multirow[b]{2}{*}{ Scintillometer } & \multicolumn{2}{|c|}{ Instrument characteristics } & \multicolumn{3}{|c|}{ Site-dependent characteristics } \\
\hline & $\begin{array}{c}\text { Wavelength } \\
{[\mathrm{m}]}\end{array}$ & $\begin{array}{c}\text { Aperture } \\
\text { diameter } \\
{[\mathrm{m}]}\end{array}$ & $\begin{array}{c}\text { Fresnel } \\
\text { zone } \\
{[\mathrm{m}]}\end{array}$ & $\begin{array}{c}\text { Effective } \\
\text { height } \\
{[\mathrm{m}]}\end{array}$ & $\begin{array}{l}\text { Scaling }(S) \\
\quad \text { factor }\end{array}$ \\
\hline $\operatorname{BLS}\left(C_{n 1 n 1}\right)$ & $880 \times 10^{-9}$ & 0.145 & - & 45.0 & - \\
\hline $\operatorname{MWS}\left(C_{n 2 n 2}\right)$ & $3.2 \times 10^{-3}$ & 0.25 & 4 & 42.8 & 0.952 \\
\hline BLS-MWS $\left(C_{n 1 n 2}\right)$ & - & - & - & 43.1 & 0.958 \\
\hline
\end{tabular}

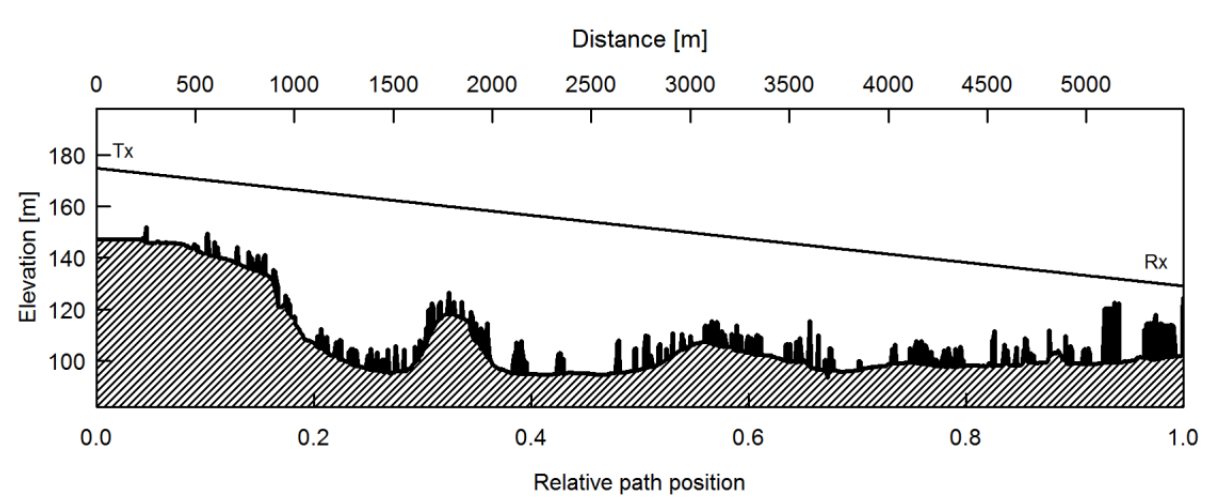

Figure 2. Cross-section of the land surface (metres above sea level) and height of obstacles (buildings and trees) along the BLS-MWS path. Tx denotes transmitter, $\mathrm{Rx}$ receiver.

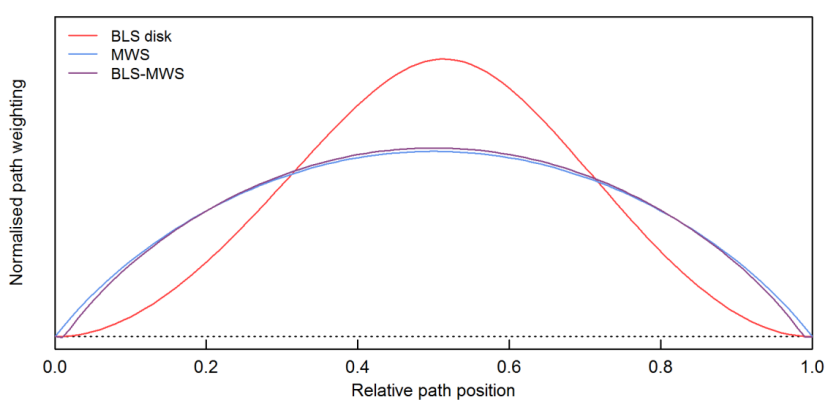

Figure 3. Path-weighting functions for the infrared scintillometer (BLS disk), the MWS and the BLS-MWS combination, normalised so that the total area under each curve equals one.

The data presented here are for the complete months when the BLS-MWS system was functioning: JulyDecember 2011 and May-December 2012. From January 2012 to April 2012 the MWS was not operational due to a fault.

\subsection{Data collection, processing and quality control}

\subsubsection{Scintillometry}

In this study, $C_{n 1 n 1}$ is used to denote the refractive index structure parameter from the BLS, to distinguish from $C_{n 2 n 2}$ (MWS) and $C_{n 1 n 2}$ (BLS-MWS cross term). The BLS900 is a dual-beam scintillometer with two transmitter disks (only one disk is used here for combination with the MWS). The signal intensity of each BLS disk was sampled and stored at $500 \mathrm{~Hz}$ (raw data) and statistics including the mean and standard deviation of signal intensity were provided at $30 \mathrm{~s}$ intervals by the Scintec software (SRun v1-07). Additionally, the signal intensities of both BLS disks and of the MWS were sampled at $100 \mathrm{~Hz}$ by a CR5000 datalogger (Campbell Scientific Ltd., Loughborough, UK). These data were processed using code written in R (The R Foundation for Statistical Computing). Data were subjected to initial quality control involving the removal of dropouts (when the BLS makes a background measurement) and despiking. The BLS and MWS signals were bandpass filtered to remove contributions below $0.06 \mathrm{~Hz}$ and above $20 \mathrm{~Hz}$ for the calculation of $C_{n 2 n 2}$ and $C_{n 1 n 2}$. The low-frequency cut-off reduces the influence of absorption fluctuations. At $10 \mathrm{~min}$ intervals, the variances, covariance and mean values of the signals were calculated, from which the log-amplitude variances $\left(\sigma_{\chi 1}^{2}, \sigma_{\chi 2}^{2}\right)$ and covariance $\left(\sigma_{\chi 1 \times 2}\right)$ were obtained (Tatarski, 1961). To convert between the log-amplitude (co)variances and refractive index (cross-)structure parameters the following equations were used:

$C_{n 1 n 1}=4.48 D^{7 / 3} L^{-3} \sigma_{\chi 1}^{2}$,
$C_{n 2 n 2}=8.33 k^{-7 / 6} L^{-11 / 6} \sigma_{\chi 2}^{2}$, 
$C_{n 1 n 2}=8.93 k^{-7 / 6} L^{-11 / 6} \sigma_{\chi 1 \times 2}$,

where $D$ refers to the aperture diameter of the infrared scintillometer, $k$ to the wave number $(2 \pi / \lambda)$ of the millimetrewave scintillometer and $L$ to the path length (Tables 1 and 2). These equations can be derived from the full forms of the logamplitude (co)variances, which express the path weighting of the instrument, the aperture averaging by the finite size of transmitter and receiver, the turbulence spectrum (assumed to be the Kolmogorov spectrum, e.g. Monin and Yaglom, 1971) and the separation of the beams if applicable (Eqs. A1 and A2, Appendix A). Note that Eq. (14c) is specific to the setup described here (beam separation, path length and instrument characteristics) and could be expressed in terms of $D$ rather than $k$. Equation (14b) was obtained using the full formula (Eq. A2) instead of the small aperture approximation (in which the Bessel functions accounting for aperture averaging are excluded) and is also specific to this setup. The approximation can result in an inaccuracy even for long paths (Appendix A). Equation (14a) for the infrared scintillometer is a standard result and was first demonstrated by Wang et al. (1978).

Quality-control procedures rejected data during periods of low signal strength (usually caused by rain or fog). BLS data were rejected when the received signal intensity dropped below 0.5 of the daily maximum value. For the MWS a threshold of 0.33 of the daily maximum intensity was used, and MWS data were also removed when the BLS signal intensity was below the 0.5 threshold indicating obscuration along the BLS-MWS path. The data points directly adjacent to those failing the signal strength checks were also removed. Rain was recorded at the EC site for $10 \%$ of the data set and fog often occurred, particularly during autumn and winter mornings (based on observations during site visits). Values of $C_{n}^{2}$ outside reasonable thresholds were excluded (nine $C_{n 1 n 1}$ values and one $C_{n 1 n 2}$ value). The resulting data available for analysis constitute $79 \%$ of the total possible 10 min values $(N=61776)$.

Kleissl et al. (2010) suggest an empirical threshold for the onset of saturation for infrared large aperture scintillometers of $C_{n 1 n 1}>0.074 D^{5 / 3} \lambda^{1 / 3} L^{-8 / 3}$. Approximately $21 \%$ of the BLS data were above this threshold of $3.2 \times 10^{-15} \mathrm{~m}^{-2 / 3}$. BLS data were corrected for saturation using a look-up table of numerical values based on the modulation transfer function of Clifford et al. (1974). The correction increased $C_{n 1 n 1}$ by around $5 \%$ overall $(\sim 10 \%$ during summer daytimes). Where the estimated correction was larger than $25 \%$, data were removed instead (46 values in total). MWS data were well below the saturation threshold of $5.0 \times 10^{-11} \mathrm{~m}^{-2 / 3}$ (Clifford et al., 1974) and were not corrected. The BLS-MWS covariance was not corrected as a methodology is yet to be determined (Beyrich et al., 2012). There is therefore increased uncertainty in these measurements due to the extent of currently applicable theory.
To use the refractive index structure parameters in Eq. (6) (or Eq. 10a-b), $C_{n 1 n 1}, C_{n 2 n 2}$ and $C_{n 1 n 2}$ must be representative of the same height. The $S$ factors (Evans and De Bruin, 2011) given in Table 2 were applied to $C_{n 2 n 2}$ from the MWS and $C_{n 1 n 2}$ from the BLS-MWS to scale them to the same effective height as $C_{n 1 n 1}$ from the BLS. These factors account for the difference in effective heights between the three $C_{n}^{2}$ measurements resulting from the combination of different weighting functions and changing beam elevation along the path (Sect. 3.1). The $S$ factors are relatively close to unity as the height differences are reasonably small for this setup. The approximation of using stability independent $S$ factors was made here (incorporating stability would give values ranging from 1.0 under very stable conditions to 0.9 for free convection). Calculation of the meteorological structure parameters proceeds as described in Sect. 2.

Data were processed using each of the three techniques in order to investigate their respective merits, although the focus is on the two-wavelength and bichromatic-correlation methods. No Bowen ratio correction was applied for the single-wavelength method (Eq. 4), given the uncertainties in estimating the available energy in urban environments. The impact is estimated to be a $6 \%$ overestimation in $C_{T}^{2}$ (based on $\beta$ from the two-wavelength method). The positions of twice-daily minima in $C_{n 1 n 1}$ were used to indicate stability transitions (Samain et al., 2012a) and assign positive or negative $r_{T q}$ for the two-wavelength method. For the two-wavelength method $r_{T q}= \pm 0.8$ was assumed and the solution corresponding to $S_{2 \lambda}=+1$ was chosen. To distinguish between the methods applied (single-wavelength, twowavelength, bichromatic-correlation), the subscripts " $1 \lambda$ ", " $2 \lambda$ " and "bc" are used.

\subsubsection{Eddy covariance}

Structure parameters were also derived from $20 \mathrm{~Hz}$ raw EC data. Sonic and IRGA data were time aligned by seeking maximum covariance between variables. Initial quality control incorporated threshold checks, outlier detection and despiking. A fixed temporal separation of $\tau=1 \mathrm{~s}$ was decided upon after investigation into suitable values in the inertial subrange. Calculation of $C_{T}^{2}, C_{q}^{2}$ and $C_{T q}$ included the Schotanus et al. (1983) correction for sonic temperature as discussed in Braam (2008) and Braam et al. (2012). No corrections were made for spectral losses caused by the spatial separation of the sonic and IRGA and their finite path lengths, which can be expected to result in underestimations of about 5-7 \% (Hill, 1991; Hartogensis et al., 2002).

The resulting $30 \mathrm{~min}$ structure parameters were quality controlled in accordance with the corresponding EC fluxes. Data were removed during times of known instrument malfunction, when the IRGA diagnostic indicated obstruction of the optical path, when rainfall could adversely affect the measurements and if values exceeded physically reasonable ranges. 

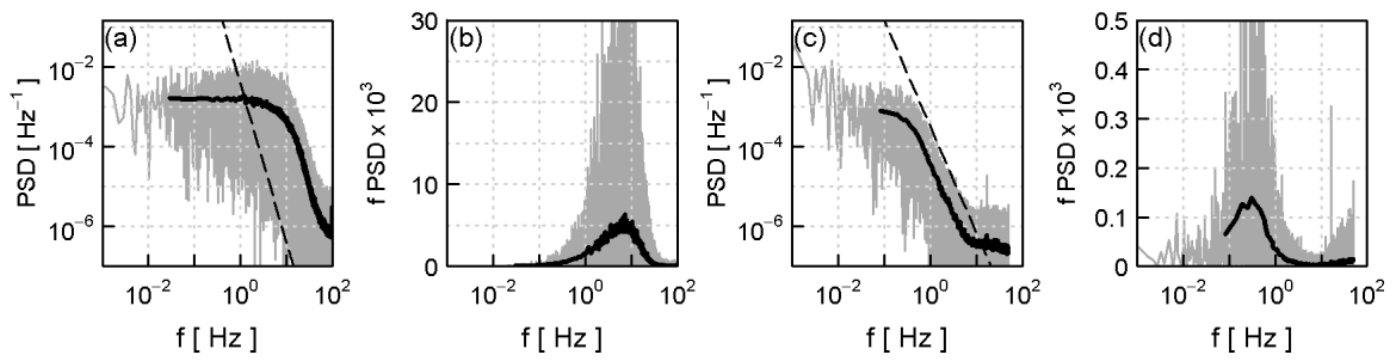

Figure 4. Example power spectral density (PSD) and frequency $(f)$ spectra for (a, b) the BLS and (c, d) unfiltered MWS for 14:3015:00 UTC on 2 July 2011. Smoothed spectra (data divided into 100 bins) are shown in black. The dashed lines represent theoretically predicted slopes of $-12 / 3$ and $-8 / 3$ for the BLS and MWS, respectively.

To facilitate comparison between EC and scintillometer data sets, the EC structure parameters were scaled to match the height of the scintillometer data using MOST functions (with the constants suggested by Andreas (1988) and assuming identical height scaling of temperature and humidity, see Eq. 3a and $b$ in Part 2).

Since the source areas are different between EC and BLSMWS systems, the structure parameters obtained are not expected to be in perfect agreement. The BLS-MWS footprint is generally more vegetated than the EC footprint (56\% versus $44 \%$ ). However, comparisons are useful for a number of reasons. As EC is a widely used technique, it permits evaluation of the scintillometer system to a certain extent, through comparison of trends and patterns of behaviour even if absolute values differ. Both systems have merits and limitations: scintillometers are spatially representative; EC is a more direct measurement but (open-path IRGAs) cannot provide data after rainfall and there are issues with energy closure (Foken, 2008). Analysis of both approaches can therefore provide a more complete picture of the environment studied.

\section{Instrument performance}

An unidentified instrumental noise problem affecting the CEH-RAL MWS has been reported elsewhere (Van Kesteren, 2008; Evans, 2009; Beyrich et al., 2012). Following extensive testing, the cause of the issue was finally established and the instrument repaired in June 2011. The spectra obtained are now close to the ideal shapes predicted by theory and suggest good instrument performance with a low noise floor (Fig. 4). An upper estimate for the MWS noise limit is $C_{n 2 n 2} \sim 1 \times 10^{-15} \mathrm{~m}^{-2 / 3}$. The observed noise limit of the BLS is of the order of $C_{n 1 n 1} \sim 5 \times 10^{-17} \mathrm{~m}^{-2 / 3}$ in agreement with the manufacturer's specification (Scintec, 2009).

\section{Results and discussion}

\subsection{Structure parameters}

\subsubsection{Refractive index structure parameters}

The refractive index structure parameters measured by the BLS $\left(C_{n 1 n 1}\right)$ and MWS $\left(C_{n 2 n 2}\right)$ and the cross-structure parameter from the covariance of the BLS-MWS signals $\left(C_{n 1 n 2}\right)$ follow clear diurnal cycles. Data for an example day are plotted in Fig. 5. Whilst $C_{n 1 n 1}$ and $C_{n 2 n 2}$ remain positive, the cross-structure parameter can be positive or negative depending on whether the infrared and millimetre-wave signals are correlated or anti-correlated. $C_{n 1 n 2}$ tends to be negative during the day and positive at night. The sign change occurs at the morning and evening stability transitions. Typically $C_{n 1 n 1}$ passes through sharp minima at these times, whereas the diurnal course of $C_{n 2 n 2}$ is flatter and wider, without clearly defined minima. These findings are in broad agreement with data from the LITFASS campaigns (Beyrich et al., 2005, 2012; Lüdi et al., 2005).

When averaged by month (Fig. 6), the diurnal patterns are enhanced and seasonal trends are revealed. The amplitudes of the diurnal cycles are largest in summer, except $C_{n 1 n 1}$ which peaks slightly earlier in the year. $C_{n 1 n 1}$ is closely related to $C_{T}^{2}$ and, in turn, the sensible heat flux. Hence the peak in $C_{n 1 n 1}$ in late spring reflects the annual cycle of $Q_{\mathrm{H}}$ : approaching maximum insolation in mid-summer, the total energy input is large but evapotranspiration rates are limited by phenological development as maximal leaf area is not reached until later in the year. During winter, low radiative input means the midday maximum in $C_{n 1 n 1}$ is small; larger values are observed at night. For millimetre wavelengths, $C_{n 2 n 2}$ tends to remain low throughout the night. The diurnal cycle in $C_{n 1 n 2}$ is maintained across all months with changes in the position of the zero crossings determined mainly by atmospheric stability (usually the sign of $Q_{\mathrm{H}}$, related to available energy and day length). In December $C_{n 1 n 2}$ is negative only for a very short period during the middle of the day. The effect of day length is also seen in the positions of $C_{n 1 n 1}$ minima, which move closer together as radiative en- 

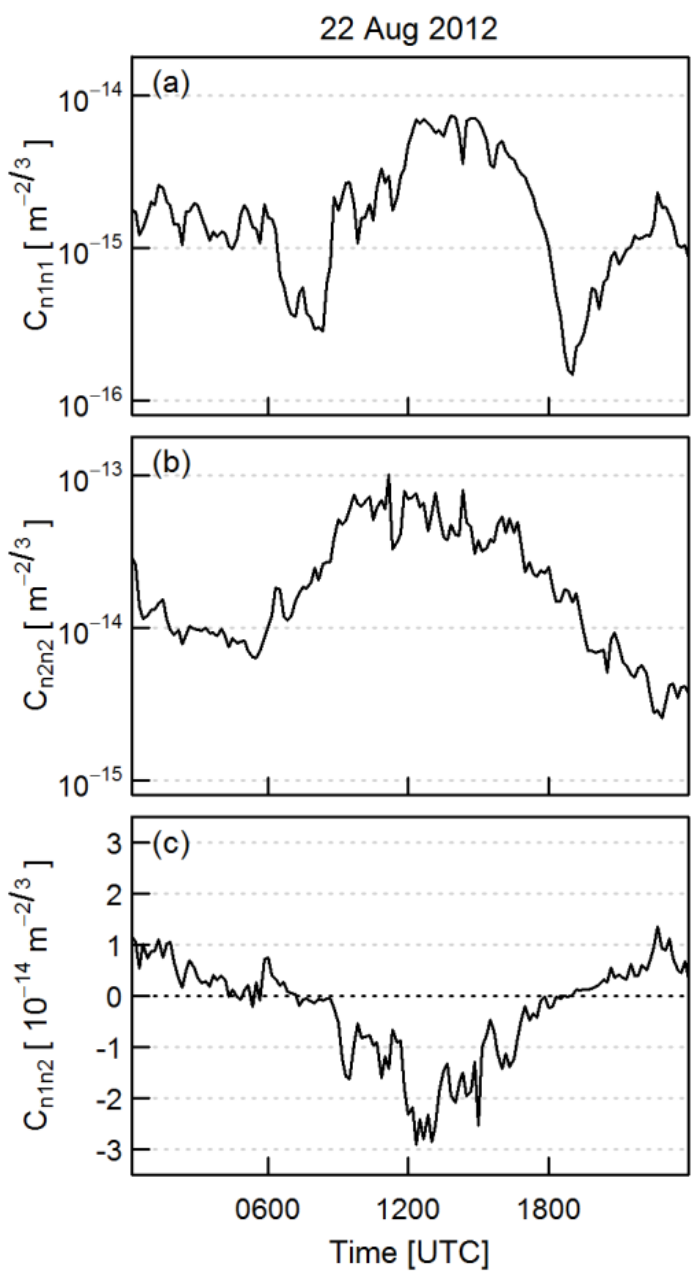

Figure 5. Structure parameters of the refractive index as measured by (a) the BLS and (b) the MWS, and (c) the cross-structure parameter as measured by the BLS-MWS combination for an example day (22 August 2012).

ergy input decreases from summer to winter. Using the positions of $C_{n 1 n 1}$ minima to indicate the stability transition times generally worked well for this data set, although performance was poorer in winter when stability changes tend to be less well defined and conditions may remain close to neutral throughout the day. Following the method described in Samain et al. (2012a), additional restrictions were imposed on the times of morning (here after 04:00 UTC) and evening (before 21:00 UTC) transitions. In a few cases, cumulative daily net radiation was also used to distinguish $C_{n 1 n 1} \mathrm{~min}$ ima that were due to sudden cloud cover during daytime from $C_{n 1 n 1}$ minima that were due to a change of stability.

\subsubsection{Meteorological structure parameters}

There are clear parallels between the refractive index structure parameters (Fig. 6) and the meteorological structure parameters (Fig. 7). $C_{n 1 n 1}$ is dominated by $C_{T}^{2}$ with a small contribution from $C_{T q}$ (of about $5 \%$, which decreases as $\beta$ increases; Green et al., 2001). The cross-structure parameter $C_{n 1 n 2}$ consists mostly of the $C_{T q}$ term and a contribution from $C_{T}^{2}$. When $C_{n 1 n 2}$ is negative $C_{T q}$ is positive. The dominant term in $C_{n 2 n 2}$ depends on the Bowen ratio: $C_{q}^{2}$ usually dominates at low $\beta$, but the $C_{T q}$ term is also important and forms a negative contribution to $C_{n 2 n 2}$ during daytime (when $C_{T q}$ is positive).

\subsubsection{Comparison of eddy covariance and scintillometry techniques}

In Fig. 8, meteorological structure parameters for individual days are compared to EC. As structure parameters are strongly height dependent, the EC values have been scaled to match the height of the scintillometry results $\left(z_{\mathrm{ef}}=45.0 \mathrm{~m}\right.$, Sect. 3.2.2). Scintillometer and EC values of $C_{T}^{2}$ and $C_{q}^{2}$ are not expected to agree exactly due to the differences in source area and land-cover composition; however, these independent measurements are often remarkably consistent. The correlation between the scintillometer and EC data sets gives confidence that the scintillometer setup is responding reasonably to changes in boundary layer conditions and measuring within the surface layer. The square of the correlation coefficient $\left(r^{2}\right)$ between the two-wavelength scintillometry and height-scaled EC data is 0.72 and 0.60 for $C_{T}^{2}$ and $C_{q}^{2}$, respectively. Considering daytime only, $r^{2}$ increases to 0.86 for $C_{T}^{2}$, but remains about the same for $C_{q}^{2}$ at 0.56 .

These results suggest $\beta_{\mathrm{EC}}$ is larger than $\beta_{\mathrm{BLS}-M w S}$, but the fact that the estimates of $C_{T}^{2}$ are closely matched while $C_{q_{-} \text {BLS-Mws }}^{2}$ is larger than $C_{q_{-} \text {EC }}^{2}$ is indicative of a more complex situation (see Part 2).

Structure parameters from the BLS-MWS and EC systems exhibit the same trends (but have different magnitudes) over the course of the year (Fig. 9). $C_{T}^{2}$ is largest during late spring, whilst $C_{q}^{2}$ peaks in July and August. There is variability between years attributed to drier conditions in 2011 than 2012 (July-August rainfall was $110 \mathrm{~mm}$ in 2011, $184 \mathrm{~mm}$ in 2012). In July-August 2011, $C_{T}^{2}$ was larger and $C_{q}^{2}$ smaller than in the same months in 2012. In general, 2012 was much wetter than 2011, which explains consistently lower $\beta$ in 2012 (Fig. 9c). The BLS-MWS gives lower $\beta$ compared to EC (during summer daytime $\beta_{\mathrm{BLS}-\mathrm{MWS}} \approx 0.5$ and $\beta_{\mathrm{EC}} \approx 1.0$ ), which is in accordance with the BLS-MWS footprint being more vegetated, but similar seasonal behaviour is seen. In winter $\beta$ becomes negative as a result of reduced radiative input, and the difference between $\beta_{\mathrm{BLS}-\mathrm{MWS}}$ and $\beta_{\mathrm{EC}}$ decreases. In terms of fluxes, evapotranspiration continues throughout winter because moisture is readily available, whereas energy is limited so $Q_{\mathrm{H}}$ is directed towards the surface for much of the daytime, only becoming positive for a short time around midday (Ward et al., 2013a). Although it is more straightforward to consider this behaviour in terms of the fluxes (discussed further in Part 2), the same conclusions 

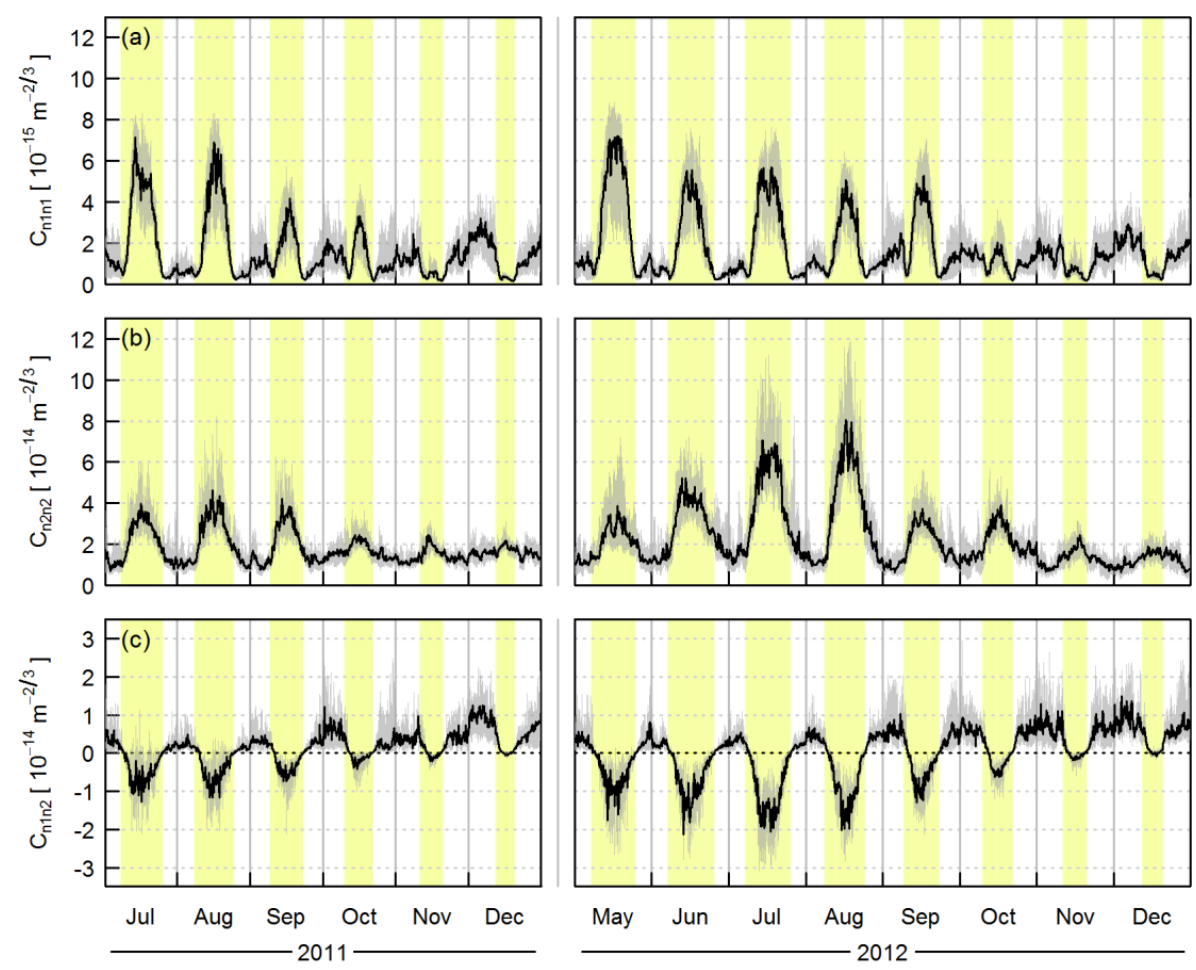

Figure 6. Median diurnal cycles and inter-quartile ranges (grey shading) of the structure parameters of the refractive index as measured by (a) the BLS and (b) the MWS, and (c) the cross-structure parameter as measured by the BLS-MWS combination, separated by month. Yellow shading indicates periods when $Q^{*}>0 \mathrm{~W} \mathrm{~m}^{-2}$.

could be inferred from the diurnal course of $r_{T q}$ (Fig. 10) and positions of $C_{n 1 n 1}$ minima (Fig. 6a).

The performance of EC and scintillometry differs with atmospheric conditions. EC data from open-path gas analysers cannot be used if the instrument windows are wet, such as during and after rainfall (Heusinkveld et al., 2008). Consequently, water vapour measurements from open-path systems significantly under-represent these times and may result in an appreciable underestimation of mean $Q_{\mathrm{E}}$ (Ramamurthy and Bou-Zeid, 2014) and $C_{q}^{2}$. Mean values for $C_{T}^{2}$ calculated using daytime data only when all quantities are available concurrently (i.e. $C_{T}^{2}$ and $C_{q}^{2}$ from EC, two-wavelength and bichromatic-correlation methods - grey bars, Fig. 9) are larger compared to mean values calculated using all available daytime data (coloured bars) due to the exclusion of periods during and directly following rain (when $C_{T}^{2}$ is typically relatively low $Q_{\mathrm{E}}$ is relatively high). In September 2012 the opposite effect is seen because the EC data were limited by dirty IRGA windows when the weather was dry and sunny; hence it is generally high $C_{T}^{2}$ values that are eliminated in this case. During summer, monthly mean $C_{q_{-} \text {BLS-MWS }}^{2}$ is reduced slightly for the concurrent data set (grey bars) as times of high $Q_{\mathrm{E}}$ when water and energy are plentiful have been excluded. The overall results are not substantially changed for the restricted subset: $C_{T_{-} \text {BLS-MWS }}^{2}$ and $C_{T_{-} \text {EC }}^{2}$ are still similar, whilst $C_{q_{-} \mathrm{BLS}-\mathrm{MWs}}^{2}$ still exceeds $C_{q_{-} \mathrm{EC}}^{2}$, although the dif- ference between $C_{q_{-} \text {BLS-MWS }}^{2}$ and $C_{q_{-} \text {EC }}^{2}$ is reduced slightly. The spectral correction (Sect. 3.3.2) would increase the EC structure parameters by 5-7\%, which would further reduce the discrepancy between EC and BLS-MWS values.

As for most previous two-wavelength campaigns, typical Bowen ratios for this path are expected to lie below the problematic region of minimum $C_{n 2 n 2}$ (Sect. 2.1). Other urban studies suggest daytime $\beta$ of around 1.0-1.5 for suburban sites, lower when precipitation is frequent (Grimmond and Oke, 1995) and strongly dependent on the amount of vegetation (Grimmond and Oke, 2002; Christen and Vogt, 2004). However, although average $\beta$ remains below 1.5 (Fig. 9c), changing surface conditions can drive down the evapotranspiration on the timescale of a few days (e.g. drying of impervious surfaces; Ward et al., 2013a, or at agricultural sites, senescing crops; Evans et al., 2012), producing substantial excursions from the average $\beta$. Such excursions are seen in this data set, particularly for $\beta_{\mathrm{EC}}$, whereas $\beta_{2 \lambda}$ seems to be limited to values $\leq 1.3$. There are two potential issues here: (a) the two-wavelength sign ambiguity and (b) the region of reduced sensitivity around the $C_{n 2 n 2}$ minimum (Sect. 2.1). Selecting $S_{2 \lambda}=+1$ automatically restricts $\beta_{2 \lambda}$ to values below that at which the terms in Equation 3 cancel out $\left(\beta_{2 \lambda \_ \text {min }}=2.0-2.6\right.$ for this data set). For a few cases (when $\beta$ is large), the "true" structure parameters should be obtained from the alternative solution $\left(S_{2 \lambda}=-1\right)$. Using the 

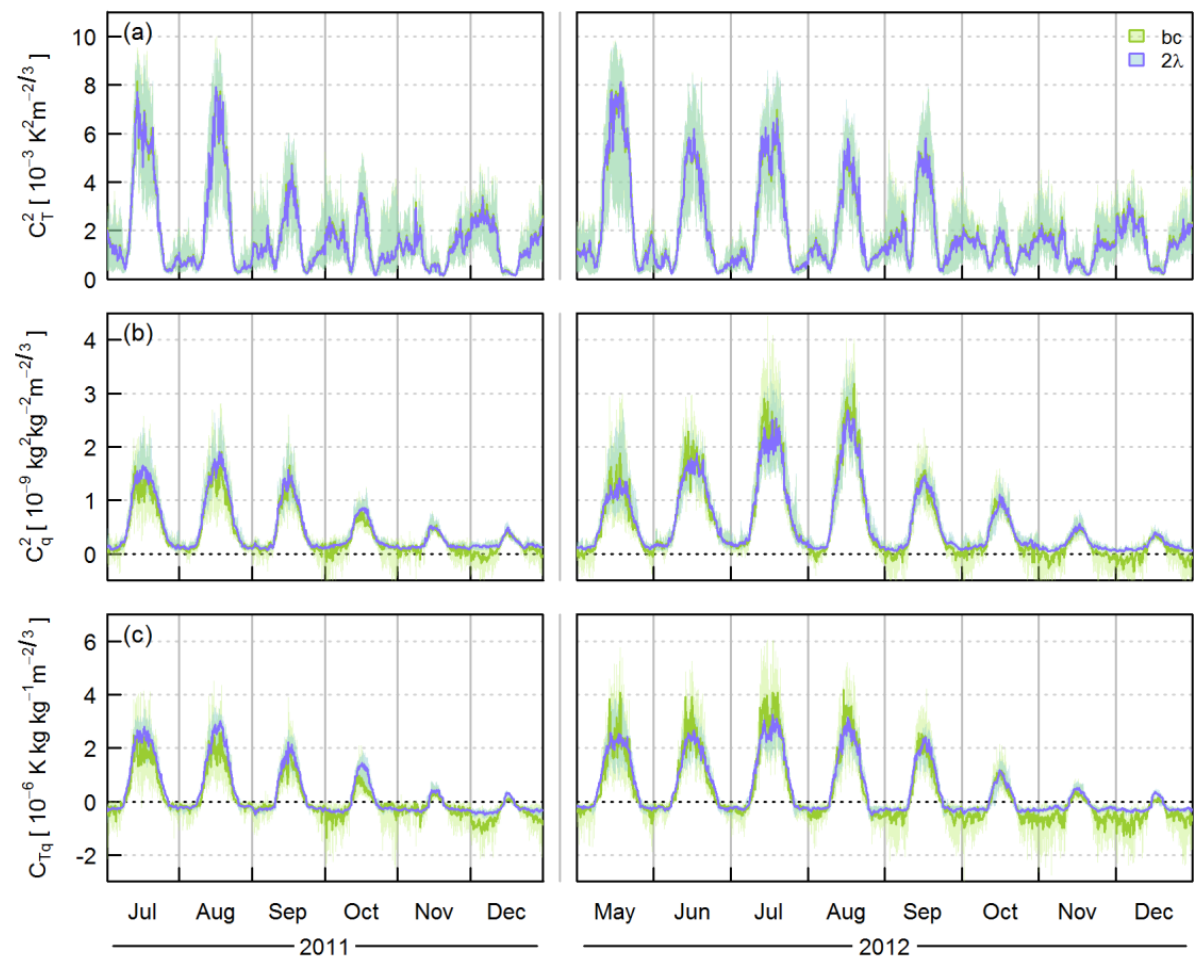

Figure 7. Median diurnal cycles and inter-quartile ranges (shading) of the meteorological structure parameters (a) $C_{T}^{2}$, (b) $C_{q}^{2}$ and (c) $C_{T q}$ calculated using the bichromatic (bc) and two-wavelength $(2 \lambda)$ techniques. In (c) $C_{T q}$ for the two-wavelength technique is given by $\pm 0.8\left(C_{T}^{2} C_{q}^{2}\right)^{1 / 2}$.

bichromatic-correlation results to identify times of high $\beta$ suggests the impact is small $\left(\beta_{\mathrm{bc}}>\beta_{2 \lambda \_ \text {min }}\right.$ for a very small proportion of the data $(<0.3 \%$ of daytime values)). A more significant issue appears to be reduced measurement capability for $\beta_{2 \lambda}>1.3$. As the true $\beta$ increases, if $C_{n 2 n 2}$ does not decrease as much as expected from theory, $\beta_{2 \lambda}$ will likely be underestimated, and the corresponding $C_{q}^{2}$ (and $Q_{\mathrm{E}}$ ) could be overestimated. It is thought that noise in the setup (instrumental or unwanted intensity fluctuations from absorption, for example) may constrain the measured value of $\beta_{2 \lambda}$ to a greater extent than suggested in the literature.

This region of reduced sensitivity of $C_{n 2 n 2}$ also compromises the performance of the bichromatic method, as measured $C_{n 2 n 2}$ will be mostly made up of noise contributions relative to the near-zero true value of $C_{n 2 n 2}$. It follows that the correlation between BLS and MWS signals in this region is expected to be dominated by common instrumental or atmospheric effects such as absorption, or any electrical interference, mounting vibrations or obscuration along the path. Although these effects were not found to be problematic generally, they could become significant when the refraction signal diminishes at moderate $\beta$.

\subsubsection{Comparison of two-wavelength and bichromatic-correlation methods}

The three estimates of $C_{T}^{2}$ for the BLS-MWS path are similar (on average within $6 \%$ ) whether the bichromaticcorrelation, two-wavelength or single-wavelength approach is used. Larger deviations are seen between $C_{q_{-} \mathrm{bc}}^{2}$ and $C_{q_{-2} \lambda}^{2}$ when measured $r_{T q_{-} \text {bc }}$ differs from the value assumed $( \pm 0.8)$ in the two-wavelength method (e.g. 21 August 2011, Fig. 8). During daytime, $C_{q_{\_} 2 \lambda}^{2}$ is slightly larger than $C_{q_{-} \mathrm{bc}}^{2}$ in 2011 but the opposite is true for most of 2012 (Figs. $\bar{b}$ b and 9b). This could be due to higher values of $r_{T q_{-} \text {bc }}$ in 2012 (see Fig. 10), which result in smaller $C_{T}^{2}$ but larger $C_{q}^{2}$ when $r_{T q}>0$. The value of $r_{T q}$ has a greater impact on $C_{q}^{2}$ than $C_{T}^{2}$ (compare error bars in Fig. 9a and b). Had $r_{T q_{-} 2 \lambda}$ been assumed to be \pm 1.0 instead of $\pm 0.8, C_{q_{-} 2 \lambda}^{2}$ would have been $7 \%$ higher and $C_{T \_2 \lambda}^{2} 1 \%$ lower.

During winter night-times, large differences are observed between $C_{q_{-} \mathrm{bc}}^{2}$ and $C_{q_{-} 2 \lambda}^{2}$ which cannot be explained by differences in $r_{T q}$. Negative values of $C_{q \_ \text {bc }}^{2}$ are frequently obtained (Fig. 7b). These do not have a physical interpretation but are indicative of measurement limitations and coincide with large negative $C_{T q_{-} \mathrm{bc}}$, which results from large positive $C_{n 1 n 2}$ (i.e. high correlation between BLS and MWS beams). Particularly during these times, but also in general, 

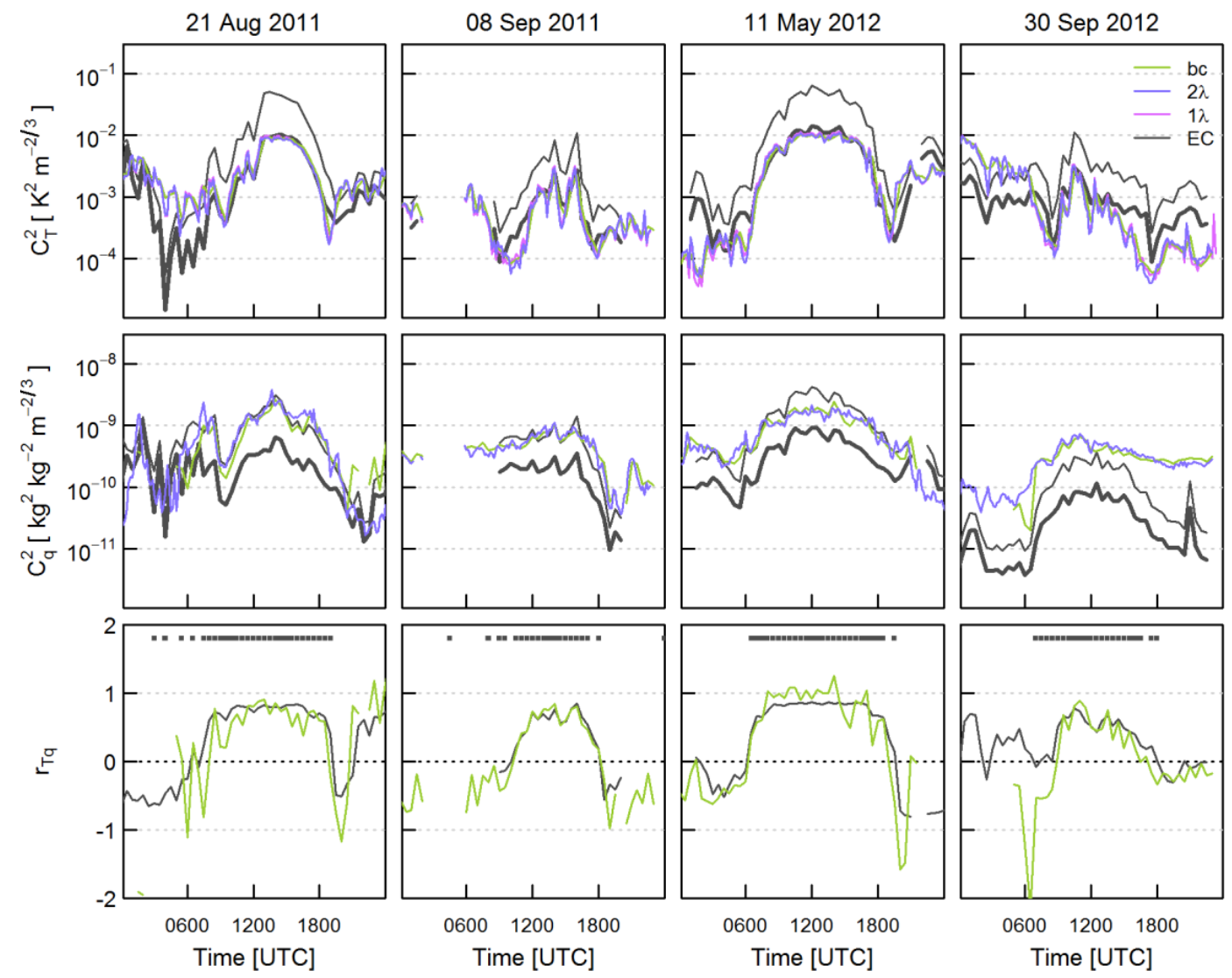

Figure 8. Structure parameters of temperature and humidity and the temperature-humidity correlation coefficient for selected days, derived from eddy covariance measurements (EC) and from the BLS-MWS system using the single-wavelength (1 $\lambda$ ), two-wavelength (2 $\lambda$ ) and bichromatic-correlation (bc) methods. EC structure parameters are shown for the EC measurement height (thin line) and scaled to the effective height of the scintillometry results (thick line). Unstable times according to the EC data $\left(L_{\mathrm{Ob}}<0\right)$ are indicated by grey dots. Single-wavelength and two-wavelength data are for $10 \mathrm{~min}$ intervals; EC and bichromatic-correlation data are for $30 \mathrm{~min}$ intervals.

the bichromatic-correlation data show much greater variability than the two-wavelength data. To reduce this variability, bichromatic-correlation data are presented as $30 \mathrm{~min}$ averages (except in Fig. 7).

\subsection{Temperature-humidity correlation}

Measured $r_{T q_{-} \text {bc }}$ follows similar seasonal and diurnal trends to $r_{T q_{-} \text {EC }}$ (Fig. 10). During summer, there is a clear plateau of around 0.8 during daytime and the transition times when $r_{T q}$ changes sign are of short duration compared to the day length. In winter $r_{T q}$ remains below zero for most of the day but peaks at positive values around midday, though the average midday $r_{T q}$ is less than 1 . The EC data rarely exceed the range -0.75 to 0.85 , whereas inspection of the time-series reveals that $r_{T q_{\text {bc }}}$ almost always follows a typical diurnal course but individual points may vary about the general trend (e.g. Fig. 8). Some unrealistic values of $\left|r_{T q_{-} \mathrm{bc}}\right|>1$ are observed, even when averaged to $30 \mathrm{~min}$ (Figs. 8 and 10). Lüdi et al. (2005) also reported frequent occurrences of $\left|r_{T q_{-} \text {bc }}\right|>1$. Since $r_{T q}$ is a correlation coef- ficient, these values $(>1)$ do not have a physical interpretation, but result from uncertainties and thus indicate limitations of the measurement. The uncertainty in $C_{n 1 n 2}$ is around $20 \%$ at best (Lüdi et al., 2005). This inherent uncertainty associated with individual measurements means the structure parameters from the bichromatic-correlation method show greater variability than from the two-wavelength method (Sect. 5.1.4), particularly $C_{q}^{2}$ and $C_{T q}$ which have a greater dependence on $C_{n 1 n 2}$ than $C_{T}^{2}$ does. For this reason, bichromatic results are presented at $30 \mathrm{~min}$, rather than $10 \mathrm{~min}$ as for the two-wavelength method (Figs. 8-11). In addition, to calculate $r_{T q}$, the structure parameters must be combined (Eq. 8) and so $r_{T q}$ amasses the uncertainties in each of the measurements.

Despite the high uncertainty, average $r_{T q}$ values provide information on the typical temperature-humidity correlation along the scintillometer path. This is an important quantity in its own right, as well as an indication of MOST violations. The literature suggests $r_{T q}$ is typically expected to be slightly less than +1 during the day, but negative and of 

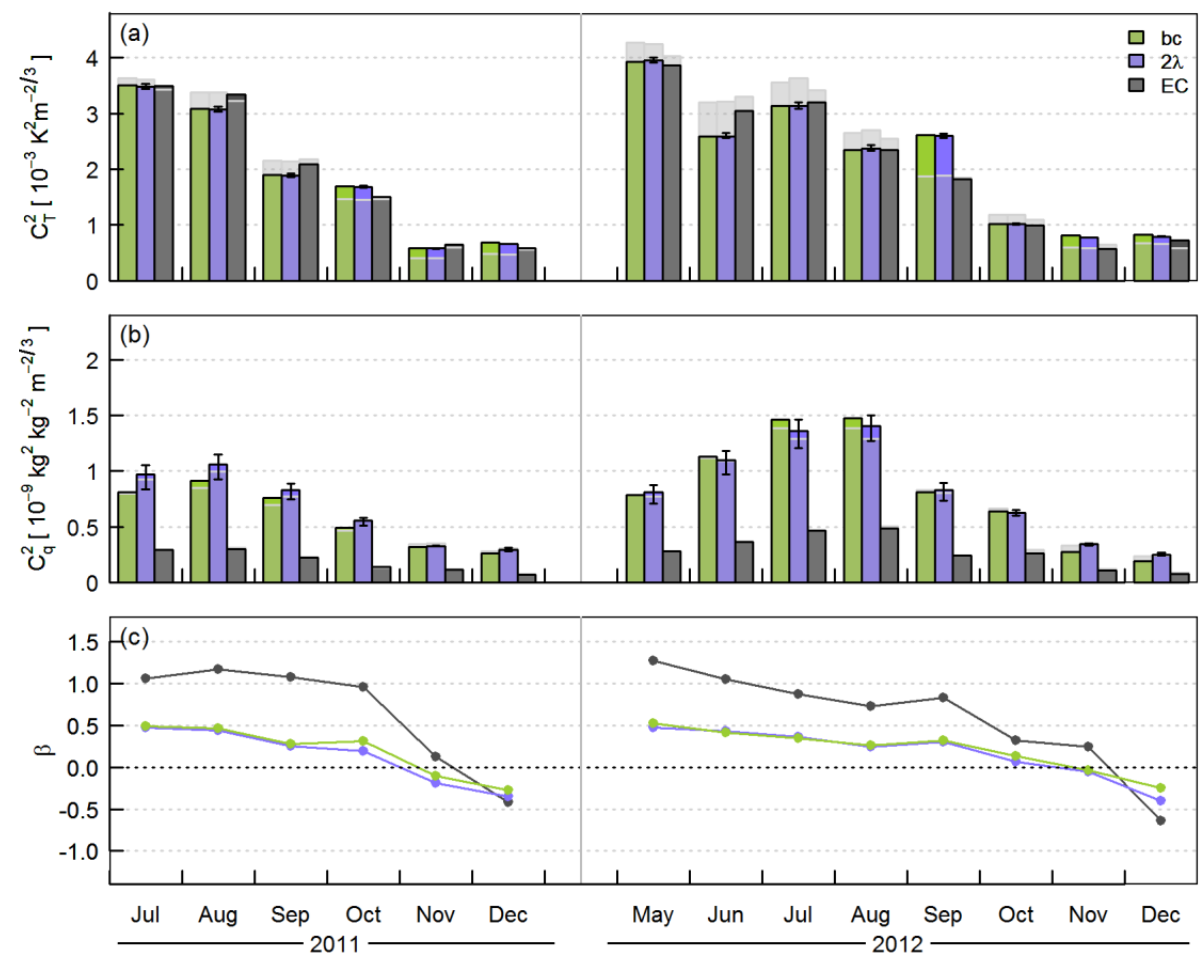

Figure 9. Mean daytime (incoming shortwave radiation $\left.K_{\downarrow}>5 \mathrm{~W} \mathrm{~m}^{-2}\right)(\mathbf{a}, \mathbf{b})$ structure parameters and (c) Bowen ratio calculated according to Eq. (9) for each month calculated for the BLS-MWS system (bichromatic-correlation and two-wavelength approaches) and eddy covariance data scaled to match the BLS-MWS height. For the two-wavelength results $r_{T q \_2 \lambda}= \pm 0.8$; error bars in (a) and (b) indicate the effect of assuming $r_{T q}$ values of \pm 0.5 and \pm 1.0 . Light grey bars $(\mathbf{a}, \mathbf{b})$ indicate means calculated when both $C_{T}^{2}$ and $C_{q}^{2}$ from all three methods (bc, $2 \lambda$ and EC) are available.
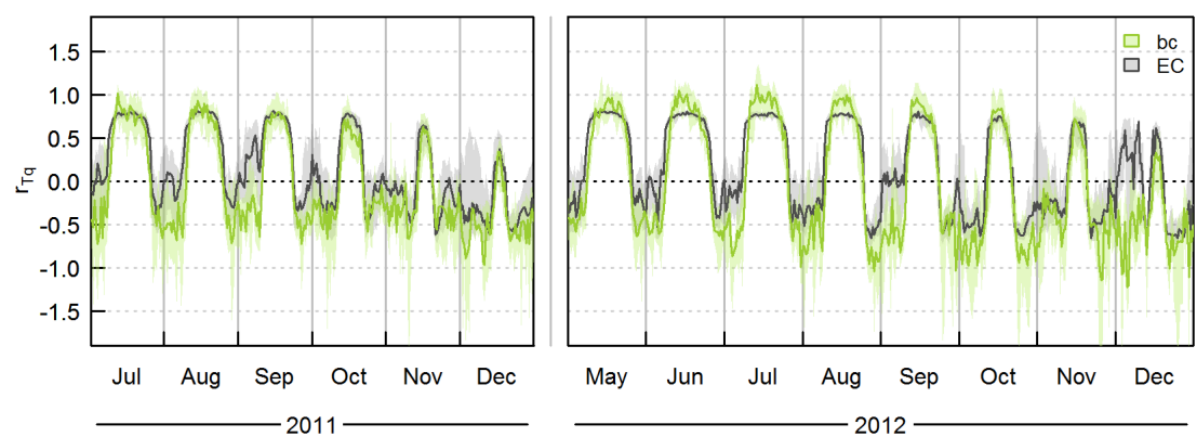

Figure 10. Monthly median diurnal cycles and inter-quartile ranges (shading) of the temperature-humidity correlation coefficient calculated from the BLS-MWS system via the bichromatic-correlation method and from EC.

smaller magnitude at night (Kohsiek, 1982; Andreas et al., 1998; Meijninger et al., 2002a; Beyrich et al., 2005). According to Lüdi et al. (2005) the $T-q$ anti-correlation observed at night is "less pronounced" than the positive correlation during daytime; Meijninger et al. (2006) also found $r_{T q}$ ranged between -0.5 and 0.9 . Our measurements conducted in the suburban environment do not indicate lower $T-q$ correlation than over other surfaces. Indeed, it is thought that $r_{T q \_ \text {EC }}$ likely underestimates the true values (as the sonic and IRGA are spatially separated). This supports the use of
MOST, and gives confidence that the measurements are made at sufficient height that the effects of surface heterogeneity are well-blended. Furthermore, the two-wavelength assumption $r_{T q}=+0.8$ is seen to be reasonable for unstable conditions, although probably $r_{T q}=-0.8$ is too large during stable conditions. Figure 10 suggests that these assumptions are less justified in winter.

In Fig. 11 values of $r_{T q}$ measured in this study are separated into unstable and stable conditions (based on $L_{\mathrm{Ob}}$ from EC data and the timing of stability transitions according to 

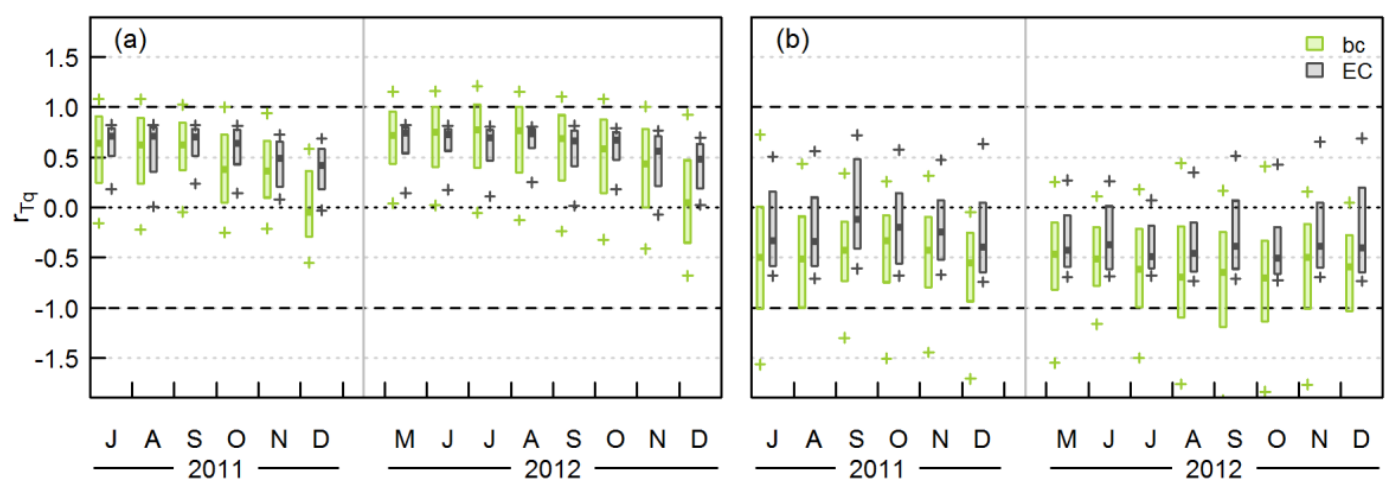

Figure 11. Box plots of $r_{T q}$ from eddy covariance (EC) and the BLS-MWS bichromatic-correlation method for (a) unstable and (b) stable conditions. Crosses indicate the 10th and 90th percentiles, boxes enclose the inter-quartile range (25th to 75 th percentiles) and heavy lines indicate the medians.

$C_{n 1 n 1}$ for the scintillometer data). During unstable conditions, measured $r_{T q}$ is positive and around 0.6 to 0.9 , whereas the stable values tend to be smaller at around -0.3 to -0.5 and more variable. In winter $r_{T q}$ is smaller and more variable (median $r_{T q_{-} \text {EC }}$ decreases from $>0.7$ in summer to $<0.5$ in December for unstable conditions). Some studies have indicated a dependence of temperature-humidity correlation on $L_{\mathrm{Ob}}$, with larger deviations from MOST as neutral conditions are approached (Li et al., 2011; Nordbo et al., 2013), although other studies differ (De Bruin et al., 1993; Roth, 1993). Part 2 further explores the scaling of temperature and humidity structure parameters with stability.

Some instances of positive nocturnal $r_{T q}$ are observed when the fluxes have the same signs, i.e. either unstable $\left(Q_{\mathrm{H}}>0\right)$ conditions prevail, or (more frequently) dewfall $\left(Q_{E}<0\right)$ is observed under stable conditions (as on 21 August 2011 after 21:30 UTC, Fig. 8). In these cases the two-wavelength method is limited as negative $r_{T q}$ must be assumed in the absence of other information, whereas the bichromatic-correlation method often captures this behaviour. In general, nocturnal structure parameters (and fluxes) tend to be small so the absolute errors introduced by $r_{T q_{-} 2 \lambda}$ of the wrong sign are fairly small, though they will always be biased in the same direction and so will accumulate over time.

The bichromatic-correlation data suggest larger daytime $r_{T q}$ in 2012 compared to 2011, but this is not seen in the EC data. The contrast between patches of hot, dry impervious areas and cool, wet vegetation may be reduced by altogether wetter surfaces in 2012, which is thought to increase correlation between temperature and humidity (Lamaud and Irvine, 2006; Moene and Schüttemeyer, 2008; Ramamurthy and Bou-Zeid, 2014). On the other hand, Lüdi et al. (2005) found lower $r_{T q}$ coincides with lower $\beta$. Experiments designed to investigate the behaviour of $r_{T q}$ (and the performance of the bichromatic-correlation technique) under different conditions would be beneficial.
In winter, and also during night-time, turbulence tends to be less well-developed. This presents challenges to measurement theory. Measurements are also more likely to be outside the surface layer when stable stratification occurs and the boundary layer height is smaller. Due to the rough surface, near-neutral conditions were far more common than stable and, for the most part, there remains a close match between the diurnal behaviour of EC and scintillometer measurements. On the few occasions when strongly stable conditions were observed at the EC station, a comparison of time series indicated periods when the BLS-MWS was possibly above the surface layer and thus potentially affected by other processes not related to surface fluxes. However, these were relatively rare occurrences.

In this study, the performance of the bichromaticcorrelation method was generally observed to be poor under conditions of low crosswind speeds (the wind speed component perpendicular to the BLS-MWS path). At times of low or near-zero crosswinds $\left(<2 \mathrm{~m} \mathrm{~s}^{-1}\right)$, the retrieved quantities are less robust, $\left|r_{T q_{-} \text {bc }}\right|>1$ is commonly observed and $r_{T q_{-} \mathrm{bc}}$ is highly variable frequently changing sign (even during the day when both turbulent fluxes are reasonably expected to be positive and EC data do not suggest otherwise). The reason for this is unknown, but two possible explanations are considered here. Firstly, Taylor's frozen turbulence hypothesis is assumed in order to relate intensity fluctuations to $C_{n}^{2}$ (Clifford, 1971; Wang et al., 1981). When crosswind speeds are low, this assumption is less justified and eddies decay as they are slowly blown through the beam. Correlation between the received scintillation pattern from one sample to the next is reduced compared to higher crosswind cases (Poggio et al., 2000). Correlation between the scintillation signals of the BLS and MWS will likely show greater variation too, depending on how the decay of eddies affects each beam, which would result in variability in $C_{n 1 n 2}$ that propagates through to $r_{T q_{-} \mathrm{bc}}$. Secondly, when wind speeds are low, turbulence may be sporadic and not well-developed over the whole path length. Perhaps sudden gusts or turbulence 
events cause spuriously high correlation between BLS and MWS signals which outweighs the correlated scintillation signal the technique aims to measure. Given the complexity of this suburban site it is difficult to draw firm conclusions on this apparent effect of crosswind on bichromatic scintillometry at this stage. Given that the position of the spectrum is known to change with wind speed (Medeiros Filho et al., 1983; Nieveen et al., 1998; Ward et al., 2011), and that $C_{n}^{2}$ can be underestimated if the filter excludes part of the scintillation signal under very low wind speed conditions (Solignac et al., 2012), the suitability of the bandpass filter was also re-examined. However, the choice of filter frequency did not seem to explain the poor performance and modifying the filter frequencies did not resolve the issues. Small changes in filter frequency generally did not produce substantial changes to the results, suggesting that the frequencies chosen are suitable for this data set, but it is not critical that those exact values are used.

\section{Conclusions}

This study reports the first use of a two-wavelength scintillometer system in an urban area. The behaviour of structure parameters and temperature-humidity correlation is investigated at various timescales. By examining the structure parameters themselves, more direct insight into the performance of the measurement techniques is gained; assessment of fluxes introduces additional uncertainties (e.g. similarity functions). Furthermore, structure parameters are important quantities in their own right. The spatial and temporal resolution of scintillometry observations offers advantages for assimilation into, or evaluation of, hydro-meteorological models. One approach for achieving this would be to work with structure parameters directly, rather than fluxes (e.g. Wood et al., 2013).

The structure parameters presented here extend previous observations to a different climatic region, different landcover type and, most importantly, across a much longer time period. Summertime behaviour is broadly in agreement with other published trials (Beyrich et al., 2005; Lüdi et al., 2005) but the long time-series presented here offers insight into seasonal variations. Day length, or more specifically, atmospheric stability, has a distinctive impact on the diurnal cycle of structure parameters and $r_{T q}$. Overall, the structure parameters obtained from the BLS-MWS and EC systems exhibit remarkably similar tendencies. The Bowen ratio calculated from the measured structure parameters decreases across the two summer-to-winter periods studied here, and $\beta_{\mathrm{BLS}-\mathrm{MWS}}$ is smaller than $\beta_{\mathrm{EC}}$, attributed partly to different source area characteristics but also probable differences between the observational techniques. Part 2 explores energy partitioning further via turbulent fluxes.

As well as extending the two-wavelength technique to a new environment, several recently developed improvements have been implemented in the processing. To obtain the structure parameter of refractive index from the millimetrewave scintillometer, the validity of the small aperture approximation is considered and the more accurate full formula used instead. To adjust for the difference in effective heights between the BLS and MWS, the $S$ factor approach of Evans and De Bruin (2011) was used. The structure parameters use the specific humidity formulation outlined in Ward et al. (2013b). The cross-correlation between BLS and MWS signals enabled estimation of the temperature-humidity correlation coefficient, thus extending the application of the bichromatic-correlation method to the suburban surface.

The bichromatic-correlation method sometimes returns values outside the physically meaningful range $\left|r_{T q}\right| \leq 1$. The inherent variability of the cross-structure parameter $C_{n 1 n 2}$ limits the accuracy of any particular measurement, whereas the two-wavelength results are more robust over shorter periods. On average, results closely follow the expected diurnal cycle of correlated temperature and humidity during the day and anti-correlated at night. Measured $r_{T q}$ is approximately $0.6-0.9$ in unstable conditions; stable values are more variable but tend to be smaller in magnitude, averaging around -0.3 to -0.5 . Observed $r_{T q}$ was furthest from \pm 1 during winter and in near-neutral conditions. Similar behaviour is seen in $r_{T q_{-} \text {bc }}$ and $r_{T q_{-} \mathrm{EC}}$, including times when the assumed two-wavelength value will be wrong.

Two-wavelength scintillometer systems have considerable potential to deliver large-area measurements representative of complex environments. Limitations of the two-wavelength method include the ambiguity due to two possible solutions for $\beta$ and the region of reduced sensitivity around the $C_{n 2 n 2}$ minimum. Research is needed; firstly, to better understand the behaviour in this region and secondly, to investigate improvements to the instrumentation, setup or post-processing to minimise the impact. Advantages of the bichromaticcorrelation method include additional information about the atmospheric conditions (e.g. the relative sign of the heat fluxes and to what extent MOST conditions are satisfied). For the minimal extra hardware requirements, the recommendation is therefore to measure the bichromatic correlation even if the additional information is not used directly in data processing.

The large proportion of vegetation and cool, wet summers helped to maintain a low Bowen ratio in this study. In drier periods or at more built-up sites, the results may have been less useable. Future work should focus on the performance of two-wavelength scintillometry under different conditions (notably low crosswind, high Bowen ratio, near-neutral stability). Theoretical development (e.g. modelling studies exploring the impact of differences in footprint and effective height between instruments) combined with careful experimental testing is needed. Comparison data (structure parameters and fluxes) from different methods will be required for thorough evaluation of these techniques. 
Appendix A: Validity of the small aperture approximation for millimetre-wave scintillometers

The log amplitude of a scintillometer system can be written in a generalised form (e.g. Lüdi et al., 2005),

$$
\begin{aligned}
\sigma_{\chi 1 \chi 2} & =4 \pi^{2} k_{1} k_{2} 0.033 C_{n}^{2} \int_{0}^{\infty} \mathrm{d} K \int_{0}^{L} \mathrm{~d} x K K^{-11 / 3} \\
& \times \sin \left(\frac{K^{2} x(L-x)}{2 k_{1} L}\right) \sin \left(\frac{K^{2} x(L-x)}{2 k_{2} L}\right) \\
& \times\left[\frac{2 J_{1}\left(0.5 K D_{\mathrm{r} 1} x / L\right)}{0.5 K D_{\mathrm{r} 1} x / L}\right]\left[\frac{2 J_{1}\left(0.5 K D_{\mathrm{t} 1}(1-x / L)\right)}{0.5 K D_{\mathrm{t} 1}(1-x / L)}\right] \\
& \times\left[\frac{2 J_{1}\left(0.5 K D_{\mathrm{r} 2} x / L\right)}{0.5 K D_{\mathrm{r} 2} x / L}\right]\left[\frac{2 J_{1}\left(0.5 K D_{\mathrm{t} 2}(1-x / L)\right)}{0.5 K D_{\mathrm{t} 2}(1-x / L)}\right] J_{0}(K|d|)
\end{aligned}
$$

where $\sigma_{\chi 1 \times 2}$ is the covariance of $\log$ amplitude, $C_{n}^{2}$ the refractive index structure parameter, $K$ the eddy wave number and $x$ the position along the path of length $L ; k$ is the optical wave number, $d$ the beam separation, and $D$ the aperture diameter of the receiver (subscript r) or transmitter (subscript t) for each instrument (subscript 1 or 2). $J_{0}$ and $J_{1}$ are Bessel functions of the first kind. The three-dimensional Kolmogorov spectrum $\Phi_{n}(K)=0.033 C_{n}^{2} K^{-11 / 3}$ is assumed.

For a single instrument, this reduces to the standard formula for a large aperture scintillometer (Hill and Ochs, 1978):

$$
\begin{aligned}
\sigma_{\chi}^{2} & =4 \pi^{2} k^{2} 0.033 C_{n}^{2} \int_{0}^{\infty} \mathrm{d} K \int_{0}^{L} \mathrm{~d} x K K^{-11 / 3} \\
& \times \sin ^{2}\left(\frac{K^{2} x(L-x)}{2 k L}\right) \times\left[\frac{2 J_{1}\left(0.5 K D_{\mathrm{r}} x / L\right)}{0.5 K D_{\mathrm{r}} x / L}\right]^{2} \\
& \times\left[\frac{2 J_{1}\left(0.5 K D_{\mathrm{t}}(1-x / L)\right)}{0.5 K D_{\mathrm{t}}(1-x / L)}\right]^{2}
\end{aligned}
$$

For cases when aperture averaging is unimportant, the standard formula for small aperture scintillometers,

$$
\begin{aligned}
\sigma_{\chi}^{2} & =4 \pi^{2} k^{2} 0.033 C_{n}^{2} \int_{0}^{\infty} \mathrm{d} K \int_{0}^{L} \mathrm{~d} x K K^{-11 / 3} \\
& \times \sin ^{2}\left(\frac{K^{2} x(L-x)}{2 k L}\right),
\end{aligned}
$$

gives

$\sigma_{\chi}^{2}=c k^{7 / 6} L^{11 / 6} C_{n}^{2}$

on integration with $c=0.124$ (Meijninger et al., 2002a, 2006; Lüdi et al., 2005).

Here we consider the validity of applying the small aperture approximation to millimetre-wave, microwave and radiowave systems. For the effects of aperture averaging to be insignificant, the aperture diameter must be sufficiently small compared to the maximal diameter of the first Fresnel zone, $F=(\lambda L)^{1 / 2}$. With $F$ around 10 times $D$, the small aperture approximation causes an appreciable $(7 \%)$ underestimation of $C_{n}^{2}$ compared to evaluating the full formula (Fig. A1). The relatively long path over Swindon means the difference between formulations is quite small here $(3 \%)$, but will be more important for shorter paths, shorter wavelengths or larger aperture diameters. Use of the full equation also modifies the path-weighting function slightly; for Swindon the difference in effective heights between using the approximation and full form is $0.15 \mathrm{~m}$. 

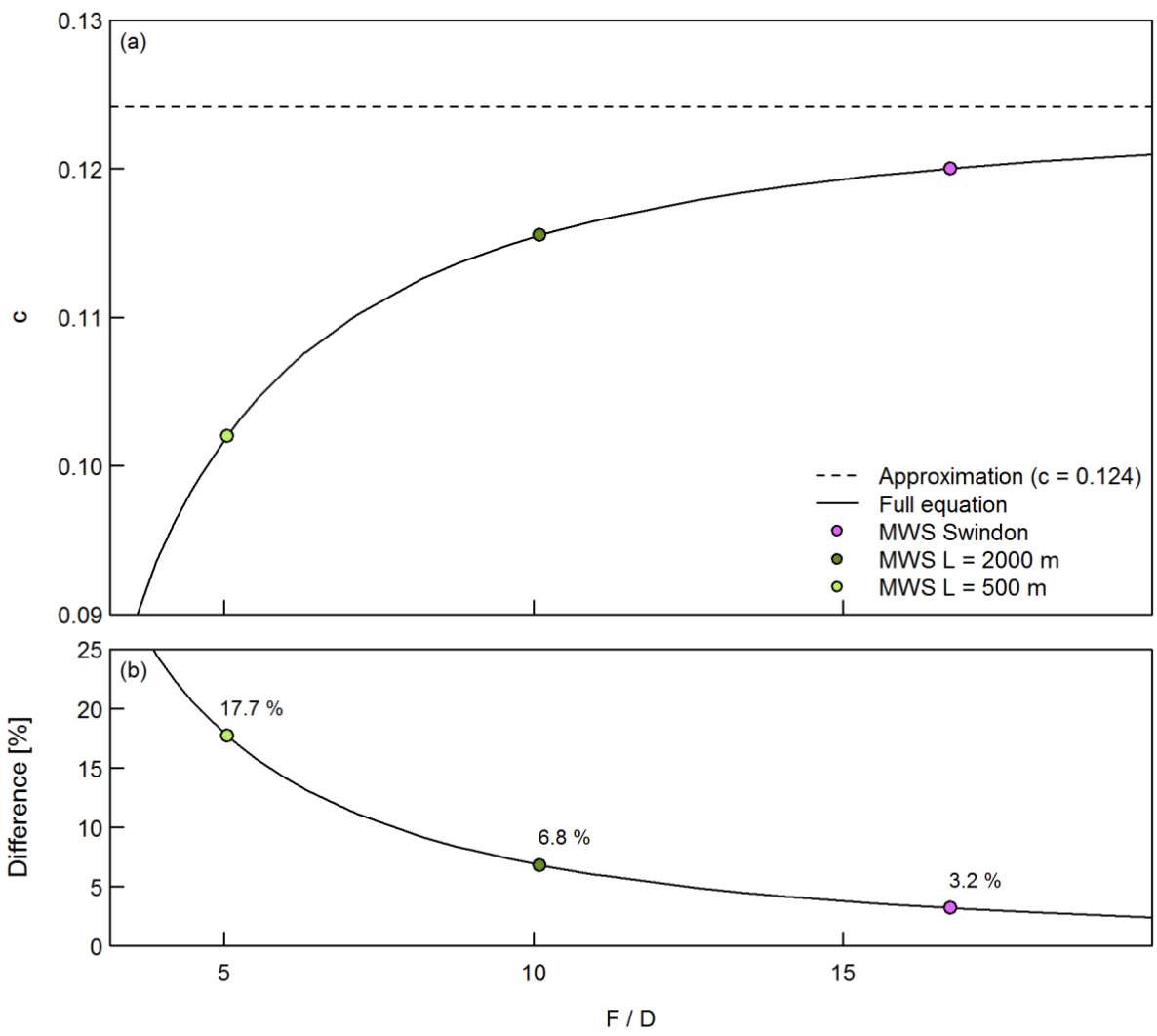

Figure A1. (a) Value of the multiplier, $c$, in Eq. (A4) when calculated using the full equation (Eq. A2) as a function of the ratio of Fresnel zone $F$ to aperture diameter $D$ and (b) percentage difference from the small aperture approximation (Eq. A3). Some example experimental setups are selected for the CEH-RAL MWS. 
Acknowledgements. We would like to thank Alan Warwick and Cyril Barrett for constructing the scintillometer mounting brackets, Geoff Wicks for assisting with the electronics and the residents of Swindon, who very kindly gave permission for equipment to be installed on their property. We are grateful to Wim Kohsiek and Oscar Hartogensis for their helpful discussions regarding the work presented in Appendix A. This work was funded by the Natural Environment Research Council, UK.

Edited by: F. S. Marzano

\section{References}

Allen, L., Lindberg, F., and Grimmond, C. S. B.: Global to city scale urban anthropogenic heat flux: model and variability, Int. J. Climatol., 31, 1990-2005, doi:10.1002/joc.2210, 2011.

Andreas, E. L.: Estimating $\mathrm{C}_{n}^{2}$ over snow and sea ice from meteorological data, J. Opt. Soc. Am., 5, 481-495, 1988.

Andreas, E. L.: Two-wavelength method of measuring pathaveraged turbulent surface heat fluxes, J. Atmos. Ocean. Tech., 6, 280-292, 1989.

Andreas, E. L.: Three-wavelength method of measuring pathaveraged turbulent heat fluxes, J. Atmos. Ocean. Tech., 7, 801814, 1990.

Andreas, E. L., Hill, R. J., Gosz, J. R., Moore, D. I., Otto, W. D., and Sarma, A. D.: Statistics of surface-layer turbulence over terrain with metre-scale heterogeneity, Bound.-Lay. Meteorol., 86, 379408, 1998.

Beyrich, F., De Bruin, H. A. R., Meijninger, W. M. L., Schipper, J. W., and Lohse, H.: Results from one-year continuous operation of a large aperture scintillometer over a heterogeneous land surface, Bound.-Lay. Meteorol., 105, 85-97, 2002.

Beyrich, F., Kouznetsov, R. D., Leps, J. P., Lüdi, A., Meijninger, W. M. L., and Weisensee, U.: Structure parameters for temperature and humidity from simultaneous eddy-covariance and scintillometer measurements, Meteorol. Z., 14, 641-649, doi:10.1127/0941-2948/2005/0064, 2005.

Beyrich, F., Bange, J., Hartogensis, O., Raasch, S., Braam, M., van Dinther, D., Gräf, D., van Kesteren, B., van den Kroonenberg, A., Maronga, B., Martin, S., and Moene, A.: Towards a Validation of Scintillometer Measurements: The LITFASS-2009 Experiment, Bound.-Lay. Meteorol., 144, 83-112, doi:10.1007/s10546-0129715-8, 2012.

Bosveld, F. C.: The KNMI Garderen experiment: micrometeorological observations 1988-1989, KNMI, the Netherlands, 57 pp., 1999.

Braam, M.: Determination of the surface sensible heat flux from the structure parameter of temperature at $60 \mathrm{~m}$ height during daytime, KNMI, the Netherlands, 42 pp., 2008.

Braam, M., Bosveld, F., and Moene, A.: On Monin-Obukhov Scaling in and Above the Atmospheric Surface Layer: The Complexities of Elevated Scintillometer Measurements, Bound.-Lay. Meteorol., 144, 157-177, doi:10.1007/s10546-012-9716-7, 2012.

Christen, A. and Vogt, R.: Energy and radiation balance of a central European city, Int. J. Climatol., 24, 1395-1421, doi:10.1002/joc.1074, 2004.
Clifford, S. F.: Temporal-frequency spectra for a spherical wave propagating through atmospheric turbulence, J. Opt. Soc. Am., 61, 1285-1292, 1971.

Clifford, S. F., Ochs, G. R., and Lawrence, R. S.: Saturation of optical scintillation by strong turbulence, J. Opt. Soc. Am., 64, 148154, 1974.

De Bruin, H. A. R., Kohsiek, W., and Van den Hurk, B. J. J. M.: A verification of some methods to determine the fluxes of momentum, sensible heat, and water-vapour using standarddeviation and structure parameter of scalar meteorological quantities, Bound.-Lay. Meteorol. 63, 231-257, 1993.

Evans, J. G.: Long-Path Scintillometry over Complex Terrain to Determine Areal-Averaged Sensible and Latent Heat Fluxes, $\mathrm{PhD}$ Thesis, Soil Science Department, the University of Reading, Reading, UK, 181 pp., 2009.

Evans, J. G. and De Bruin, H. A. R.: The Effective Height of a TwoWavelength Scintillometer System, Bound.-Lay. Meteorol., 141, 165-177, doi:10.1007/s10546-011-9634-0, 2011.

Evans, J. G., McNeil, D. D., Finch, J. F., Murray, T., Harding, R. J., and Verhoef, A.: Evaporation Measurements at Kilometre Scales Determined Using Two-wavelength Scintillometry. BHS Third International Symposium, Role of Hydrology in Managing Consequences of a Changing Global Environment Newcastle University, 19-23 July 2010, Newcastle upon Tyne, UK, 2010.

Evans, J. G., McNeil, D. D., Finch, J. W., Murray, T., Harding, R. J., Ward, H. C., and Verhoef, A.: Determination of turbulent heat fluxes using a large aperture scintillometer over undulating mixed agricultural terrain, Agr. Forest Meteorol., 166-167, 221233, 2012.

Ezzahar, J., Chehbouni, A., and Hoedjes, J. C. B.: On the application of scintillometry over heterogeneous grids, J. Hydrol., 334, 493-501, doi:10.1016/j.jhydrol.2006.10.027, 2007.

Ezzahar, J., Chehbouni, A., Hoedjes, J., Ramier, D., Boulain, N., Boubkraoui, S., Cappelaere, B., Descroix, L., Mougenot, B., and Timouk, F.: Combining scintillometer measurements and an aggregation scheme to estimate area-averaged latent heat flux during the AMMA experiment, J. Hydrol., 375, 217-226, doi:10.1016/j.jhydrol.2009.01.010, 2009.

Foken, T.: The energy balance closure problem: An overview, Ecol. Appl., 18, 1351-1367, 2008.

Garratt, J. R.: Transfer characteristics for a heterogeneous surface of large aerodynamic roughness, Q. J. Roy. Meteorol. Soc., 104, 491-502, doi:10.1002/qj.49710444019, 1978.

Garratt, J. R.: The Atmospheric Boundary Layer, Cambridge University Press, Cambridge, UK, 316 pp., 1992.

Gouvea, M. L. and Grimmond, C. S. B.: Spatially integrated measurements of sensible heat flux using scintillometry, Ninth Symposium on the Urban Environment, 2-6 August 2010, Keystone, Colorado, 2010.

Green, A. E. and Hayashi, Y.: Use of the scintillometer technique over a rice paddy, Japan. J. Agr. Meteorol., 54, 225-231, 1998.

Green, A. E., Astill, M. S., McAneney, K. J., and Nieveen, J. P.: Path-averaged surface fluxes determined from infrared and microwave scintillometers, Agr. Forest Meteorol., 109, 233-247, 2001.

Grimmond, C. S. B. and Oke, T. R.: Comparison of Heat Fluxes from Summertime Observations in the Suburbs of Four North American Cities, J. Appl. Meteorol., 34, 873-889, 
doi:10.1175/1520-0450(1995)034<0873:COHFFS>2.0.CO;2, 1995.

Grimmond, C. S. B. and Oke, T. R.: Aerodynamic properties of urban areas derived from analysis of surface form, J. Appl. Meteorol., 38, 1262-1292, 1999.

Grimmond, C. S. B. and Oke, T. R.: Turbulent heat fluxes in urban areas: Observations and a local-scale urban meteorological parameterization scheme (LUMPS), J. Appl. Meteorol., 41, 792$810,2002$.

Guyot, A., Cohard, J.-M., Anquetin, S., Galle, S., and Lloyd, C. R.: Combined analysis of energy and water balances to estimate latent heat flux of a sudanian small catchment, J. Hydrol., 375, 227-240, 2009

Hartogensis, O. K., De Bruin, H. A. R., and Van De Wiel, B. J. H.: Displaced-Beam Small Aperture Scintillometer Test, Part Ii: Cases-99 Stable Boundary-Layer Experiment, Bound.-Lay. Meteorol., 105, 149-176, doi:10.1023/a:1019620515781, 2002.

Hartogensis, O. K., Watts, C. J., Rodriguez, J. C., and De Bruin, H. A. R.: Derivation of an effective height for scintillometers: La Poza experiment in Northwest Mexico, J. Hydrometerol., 4, 915-928, 2003

Heusinkveld, B. G., Jacobs, A. F. G., and Holtslag, A. A. M.: Effect of open-path gas analyzer wetness on eddy covariance flux measurements: A proposed solution, Agr. Forest Meteorol., 148, 1563-1573, doi:10.1016/j.agrformet.2008.05.010, 2008.

Hill, R. J.: Implications of Monin-Obukhov Similarity Theory for Scalar Quantities, J. Atmos. Sci., 46, 2236-2244, 1989.

Hill, R. J.: Comparison of experiment with a new theory of the turbulence temperature structure-function, Phys. Fluids A, 3, 15721576, doi:10.1063/1.857936, 1991.

Hill, R. J.: Algorithms for obtaining atmospheric surface-layer fluxes from scintillation measurements, J. Atmos. Ocean. Tech., 14, 456-467, 1997.

Hill, R. J. and Ochs, G. R.: Fine calibration of large-aperture optical scintillometers and an optical estimate of inner scale of turbulence, Appl. Optics, 17, 3608-3612, 1978.

Hill, R. J., Clifford, S. F., and Lawrence, R. S.: Refractive-index and absorption fluctuations in the infrared caused by temperature, humidity, and pressure fluctuations, J. Opt. Soc. Am., 70, 1192-1205, 1980.

Hill, R. J., Bohlander, R. A., Clifford, S. F., McMillan, R. W., Priestly, J. T., and Schoenfeld, W. P.: Turbulence-induced millimeter-wave scintillation compared with micrometeorological measurements, IEEE T. Geosci. Remote, 26, 330-342, 1988.

Hoedjes, J. C. B., Zuurbier, R. M., and Watts, C. J.: Large aperture scintillometer used over a homogeneous irrigated area, partly affected by regional advection, Bound.-Lay. Meteorol., 105, 99$117,2002$.

Kanda, M., Moriwaki, R., Roth, M., and Oke, T.: Area-averaged sensible heat flux and a new method to determine zero-plane displacement length over an urban surface using scintillometry, Bound.-Lay. Meteorol., 105, 177-193, 2002.

Kleissl, J., Hartogensis, O., and Gomez, J.: Test of Scintillometer Saturation Correction Methods Using Field Experimental Data, Bound.-Lay. Meteorol., 137, 493-507, doi:10.1007/s10546-0109540-x, 2010.

Klysik, K.: Spatial and seasonal distribution of anthropogenic heat emissions in Łdź, Poland, Atmos. Environ., 30, 3397-3404, 1996.
Kohsiek, W.: Measuring $C_{T}^{2}, C_{Q}^{2}$, and $C_{T Q}$ in the Unstable Surface-Layer, and Relations to the Vertical Fluxes of Heat and Moisture, Bound.-Lay. Meteorol., 24, 89-107, 1982.

Kohsiek, W. and Herben, M. H. A. J.: Evaporation derived from optical and radio-wave scintillation, Appl. Optics, 22, 2566-2570, 1983.

Lagouarde, J. P., Irvine, M., Bonnefond, J. M., Grimmond, C. S. B., Long, N., Oke, T. R., Salmond, J. A., and Offerle, B.: Monitoring the sensible heat flux over urban areas using large aperture scintillometry: Case study of Marseille city during the ESCOMPTE experiment, Bound.-Lay. Meteorol., 118, 449-476, doi:10.1007/s10546-005-9001-0, 2006.

Lamaud, E. and Irvine, M.: Temperature-Humidity Dissimilarity and Heat-to-water-vapour Transport Efficiency Above and Within a Pine Forest Canopy: the Role of the Bowen Ratio, Bound.-Lay. Meteorol., 120, 87-109, doi:10.1007/s10546-0059032-6, 2006.

Leijnse, H., Uijlenhoet, R., and Stricker, J. N. M.: Hydrometeorological application of a microwave link: 1. Evaporation, Water Resour. Res., 43, W04416, doi:10.1029/2006wr004988, 2007.

Li, D., Bou-Zeid, E., and De Bruin, H. A. R.: Monin-Obukhov Similarity Functions for the Structure Parameters of Temperature and Humidity, Bound.-Lay. Meteorol., 145, 45-67, doi:10.1007/s10546-011-9660-y, 2011.

Lüdi, A., Beyrich, F., and Matzler, C.: Determination of the turbulent temperature-humidity correlation from scintillometric measurements, Bound.-Lay. Meteorol., 117, 525-550, doi:10.1007/s10546-005-1751-1, 2005.

Medeiros Filho, F., Jayasuriya, D., Cole, R., and Helmis, C.: Spectral density of millimeter wave amplitude scintillations in an absorption region, IEEE T. Anten. Propag., 31, 672-676, 1983.

Meijninger, W. M. L.: Surface fluxes over natural landscapes using scintillometry, $\mathrm{PhD}$ Thesis, Meteorology and Air Quality Group, Wageningen University, Wageningen, the Netherlands, 170 pp., 2003.

Meijninger, W. M. L., Green, A. E., Hartogensis, O. K., Kohsiek, W., Hoedjes, J. C. B., Zuurbier, R. M., and De Bruin, H. A. R.: Determination of area-averaged water vapour fluxes with large aperture and radio wave scintillometers over a heterogeneous surface - Flevoland field experiment, Bound.-Lay. Meteorol., 105, 63-83, 2002a.

Meijninger, W. M. L., Hartogensis, O. K., Kohsiek, W., Hoedjes, J. C. B., Zuurbier, R. M., and De Bruin, H. A. R.: Determination of area-averaged sensible heat fluxes with a large aperture scintillometer over a heterogeneous surface - Flevoland field experiment, Bound.-Lay. Meteorol., 105, 37-62, 2002b.

Meijninger, W. M. L., Beyrich, F., Lüdi, A., Kohsiek, W., and De Bruin, H. A. R.: Scintillometer-based turbulent fluxes of sensible and latent heat over a heterogeneous land surface - A contribution to LITFASS-2003, Bound.-Lay. Meteorol., 121, 89-110, doi:10.1007/s10546-005-9022-8, 2006.

Mestayer, P., Bagga, I., Calmet, I., Fontanilles, G., Gaudin, D., Lee, J. H., Piquet, T., Rosant, J.-M., Chancibault, K., Lebouc, L., Letellier, L., Mosini, M.-L., Rodriguez, F., Rouaud, J.-M., Sabre, M., Tétard, Y., Brut, A., Selves, J.-L., Solignac, P.-A., Brunet, Y., Dayau, S., Irvine, M., Lagouarde, J.-P., Kassouk, Z., Launeau, P., Connan, O., Defenouillère, P., Goriaux, M., Hébert, D., Letellier, B., Mario, D., Najjar, G., Nerry, F., Quentin, C., Biron, R., Cohard, J.-M., Galvez, J., and Klein, P.: The FluxSAP 2010 hy- 
droclimatological experimental campaign over an heterogeneous urban area, 11th EMS Annual Meeting, 12-16 September 2011, Berlin, Germany, 2011.

Moene, A. F.: Effects of water vapour on the structure parameter of the refractive index for near-infrared radiation, Bound.-Lay. Meteorol., 107, 635-653, 2003.

Moene, A. F. and Schüttemeyer, D.: The Effect of Surface Heterogeneity on the Temperature-Humidity Correlation and the Relative Transport Efficiency, Bound.-Lay. Meteorol., 129, 99-113, doi:10.1007/s10546-008-9312-z, 2008.

Monin, A. S. and Yaglom, A. M.: Statistical Fluid Mechanics: Mechanics of Turbulence, The MIT Press, Cambridge, Massachusetts, 782 pp., 1971.

Nieveen, J. P., Green, A. E., and Kohsiek, W.: Using a large-aperture scintillometer to measure absorption and refractive index fluctuations, Bound.-Lay. Meteorol., 87, 101-116, 1998.

Nordbo, A., Järvi, L., Haapanala, S., Moilanen, J., and Vesala, T.: Intra-City Variation in Urban Morphology and Turbulence Structure in Helsinki, Finland, Bound.-Lay. Meteorol., 146, 469-496, doi:10.1007/s10546-012-9773-y, 2013.

Offerle, B., Grimmond, C. S. B., and Fortuniak, K.: Heat storage and anthropogenic heat flux in relation to the energy balance of a central European city centre, Int. J. Climatol., 25, 1405-1419, doi:10.1002/joc.1198, 2005.

Oke, T. R.: Boundary Layer Climates, Routledge, Taylor and Francis Group, London, UK, 435 pp., 1987.

Otto, W. D., Hill, R. J., Sarma, A. D., Wilson, J. J., Andreas, E. L., Gosz, J. R., and Moore, D. I.: Results of the Millimeter-Wave Instrument Operated at Sevilleta, New Mexico, NOAA-TM-ERLETL-262, NOAA Environmental Reasearch Laboratories, Boulder, Colorado, 47 pp., 1996.

Pasquill, F.: Atmospheric Diffusion, Wiley, New York, 429 pp., 1974.

Pauscher, L.: Scintillometer Measurements above the Urban Area of London. Department of Micrometeorology, University of Bayreuth, Bayreuth, Germany, 104 pp., 2010.

Poggio, L. P., Furger, M., Prevot, A. S. H., Graber, W. K., and Andreas, E. L.: Scintillometer wind measurements over complex terrain, J. Atmos. Ocean. Tech., 17, 17-26, 2000.

Ramamurthy, P. and Bou-Zeid, E.: Contribution of impervious surfaces to urban evaporation, Water Resour. Res., 50, 2889-2902, doi:10.1002/2013WR013909, 2014.

Roth, M.: Turbulent transfer relationships over an urban surface, II: Integral statistics, Q. J. Roy. Meteorol. Soc., 119, 1105-1120, doi:10.1002/qj.49711951312, 1993.

Roth, M., Salmond, J. A., and Satyanarayana, A. N. V.: Methodological considerations regarding the measurement of turbulent fluxes in the urban roughness sublayer: The role of scintillometery, Bound.-Lay. Meteorol., 121, 351-375, doi:10.1007/s10546006-9074-4, 2006.

Samain, B., Defloor, W., and Pauwels, V. R. N.: Continuous Time Series of Catchment-Averaged Sensible Heat Flux from a Large Aperture Scintillometer: Efficient Estimation of Stability Conditions and Importance of Fluxes under Stable Conditions, J. Hydrometerol., 13, 423-442, doi:10.1175/jhm-d-11-030.1, 2012a.

Samain, B., Simons, G. W. H., Voogt, M. P., Defloor, W., Bink, N.-J., and Pauwels, V. R. N.: Consistency between hydrological model, large aperture scintillometer and remote sensing based evapotranspiration estimates for a heterogeneous catchment, Hy- drol. Earth Syst. Sci., 16, 2095-2107, doi:10.5194/hess-16-20952012, 2012b.

Schotanus, P., Nieuwstadt, F. T. M., and Bruin, H. A. R.: Temperature measurement with a sonic anemometer and its application to heat and moisture fluxes, Bound.-Lay. Meteorol., 26, 81-93, doi:10.1007/bf00164332, 1983.

Scintec: Scintec Boundary Layer Scintillometer Hardware Manual, Rottenburg, Germany, 67 pp., 2009.

Solignac, P. A., Brut, A., Selves, J.-L., Béteille, J.-P., GastelluEtchegorry, J.-P., Keravec, P., Béziat, P., and Ceschia, E.: Uncertainty analysis of computational methods for deriving sensible heat flux values from scintillometer measurements, Atmos. Meas. Tech., 2, 741-753, doi:10.5194/amt-2-741-2009, 2009.

Solignac, P. A., Brut, A., Selves, J. L., Béteille, J. P., and GastelluEtchegorry, J. P.: Attenuating the Absorption Contribution on $C_{n}^{2}$ Estimates with a Large-Aperture Scintillometer, Bound.Lay. Meteorol., 143, 261-283, doi:10.1007/s10546-011-9692-3, 2012.

Stull, R. B.: An Introduction to Boundary Layer Meteorology, Kluwer Academic Publishers, Dordrecht, the Netherlands, 666 pp., 1988.

Tatarski, V. I.: Wave Propagation in a Turbulent Medium, McGrawHill, New York, 285 pp., 1961.

Van Kesteren, A. J. H.: Sensible and Latent Heat Fluxes with Optical and Millimetre Wave Scintillometers: A Theory Review and the Chilbolton Experiment, Masters Thesis, Wageningen University, Wageningen, the Netherlands, 99 pp., 2008.

Von Randow, C., Kruijt, B., Holtslag, A. A. M., and de Oliveira, M. B. L.: Exploring eddy-covariance and large-aperture scintillometer measurements in an Amazonian rain forest, Agr. Forest Meteorol., 148, 680-690, doi:10.1016/j.agrformet.2007.11.011, 2008.

Wang, T. I., Ochs, G. R., and Clifford, S. F.: A saturation-resistant optical scintillometer to measure $C_{n}^{2}$, J. Opt. Soc. Am., 68, 334338, 1978.

Wang, T. I., Ochs, G. R., and Lawrence, R. S.: Wind measurements by the temporal cross-correlation of the optical scintillations, Appl. Optics, 20, 4073-4081, 1981.

Ward, H. C., Evans, J. G., and Grimmond, C. S. B.: Effects of NonUniform Crosswind Fields on Scintillometry Measurements, Bound.-Lay. Meteorol., 141, 143-163, doi:10.1007/s10546-0119626-0, 2011.

Ward, H. C., Evans, J. G., and Grimmond, C. S. B.: Multi-season eddy covariance observations of energy, water and carbon fluxes over a suburban area in Swindon, UK, Atmos. Chem. Phys., 13, 4645-4666, doi:10.5194/acp-13-4645-2013, 2013a.

Ward, H. C., Evans, J. G., Hartogensis, O. K., Moene, A. F., De Bruin, H. A. R., and Grimmond, C. S. B.: A critical revision of the estimation of the latent heat flux from two-wavelength scintillometry, Q. J. Roy. Meteorol. Soc., 139, 1912-1922, doi:10.1002/qj.2076, 2013b.

Ward, H. C., Evans, J. G., and Grimmond, C. S. B.: Infrared and millimetre-wave scintillometry in the suburban environment Part 2: Large-area sensible and latent heat fluxes, Atmos. Meas. Tech., 8, 1407-1424, doi:10.5194/amt-8-1407-2015, 2015.

Wesely, M. L.: Combined effect of temperature and humidity fluctuations on refractive-index, J. Appl. Meteorol., 15, 43-49, 1976.

Wood, C. R., Kouznetsov, R. D., Gierens, R., Nordbo, A., Järvi, L., Kallistratova, M. A., and Kukkonen, J.: On the Temperature 
Structure Parameter and Sensible Heat Flux over Helsinki from Sonic Anemometry and Scintillometry, J. Atmos. Ocean. Tech., 30, 1604-1615, doi:10.1175/JTECH-D-12-00209.1, 2013.
Zielinski, M., Fortuniak, K., Pawlak, W., and Siedlecki, M.: Turbulent sensible heat flux in Łódź, Central Poland, obtained from scintillometer and eddy covariance measurements, Meteorol. Z., 22, 603-613, 2013. 